\title{
Methamphetamine Regulation of Firing Activity of Dopamine Neurons
}

\author{
Min Lin, Danielle Sambo, and $\odot$ Habibeh Khoshbouei \\ Department of Neuroscience, Evelyn F. and William L. McKnight Brain Institute, University of Florida, Gainesville, Florida 32610
}

Methamphetamine (METH) is a substrate for the dopamine transporter that increases extracellular dopamine levels by competing with dopamine uptake and increasing reverse transport of dopamine via the transporter. METH has also been shown to alter the excitability of dopamine neurons. The mechanism of METH regulation of the intrinsic firing behaviors of dopamine neurons is less understood. Here we identified an unexpected and unique property of METH on the regulation of firing activity of mouse dopamine neurons. METH produced a transient augmentation of spontaneous spike activity of midbrain dopamine neurons that was followed by a progressive reduction of spontaneous spike activity. Inspection of action potential morphology revealed that METH increased the half-width and produced larger coefficients of variation of the interspike interval, suggesting that METH exposure affected the activity of voltage-dependent potassium channels in these neurons. Since METH has been shown to affect $\mathrm{Ca}^{2+}$ homeostasis, the unexpected findings that METH broadened the action potential and decreased the amplitude of afterhyperpolarization led us to ask whether METH alters the activity of $\mathrm{Ca}^{2+}$-activated potassium (BK) channels. First, we identified BK channels in dopamine neurons by their voltage dependence and their response to a BK channel blocker or opener. While METH suppressed the amplitude of BK channel-mediated unitary currents, the BK channel opener NS1619 attenuated the effects of METH on action potential broadening, afterhyperpolarization repression, and spontaneous spike activity reduction. Live-cell total internal reflection fluorescence microscopy, electrophysiology, and biochemical analysis suggest METH exposure decreased the activity of BK channels by decreasing BK- $\alpha$ subunit levels at the plasma membrane.

Key words: amphetamines; BK channels; Ca-activated K channels; dopamine; dopamine neurons; dopamine transporter

\section{Significance Statement}

Methamphetamine (METH) competes with dopamine uptake, increases dopamine efflux via the dopamine transporter, and affects the excitability of dopamine neurons. Here, we identified an unexpected property of METH on dopamine neuron firing activity. METH transiently increased the spontaneous spike activity of dopamine neurons followed by a progressive reduction of the spontaneous spike activity. METH broadened the action potentials, increased coefficients of variation of the interspike inter$\mathrm{val}$, and decreased the amplitude of afterhyperpolarization, which are consistent with changes in the activity of $\mathrm{Ca}^{2+}$-activated potassium (BK) channels. We found that METH decreased the activity of BK channels by stimulating BK- $\alpha$ subunit trafficking. Thus, METH modulation of dopamine neurotransmission and resulting behavioral responses is, in part, due to METH regulation of BK channel activity.

\section{Introduction}

Methamphetamine (METH) regulates dopamine neurotransmission through a variety of mechanisms (Kogan et al., 1976). METH competes with dopamine uptake and stimulates dopa-

\footnotetext{
Received April 27, 2016; revised Aug. 17, 2016; accepted Aug. 18, 2016.

Author contributions: M.L. and H.K. designed research; M.L., D.S., and H.K. performed research; M.L., D.S., and H.K. analyzed data; M.L., D.S., and H.K. wrote the paper.

This work was supported by National Institutes of Health Grants DA026947, NS071122, 0D020026, and DA026947S1.

The authors declare no competing financial interests.

Correspondence should be addressed to Habibeh Khoshbouei, P.O. Box 100244, Gainesville, FL 32610-0015. E-mail: habibeh@ufl.edu.

DOI:10.1523/JNEUROSCI.1392-16.2016

Copyright $\odot 2016$ the authors $\quad 0270-6474 / 16 / 3610376-16 \$ 15.00 / 0$
}

mine efflux via the dopamine transporter (Bennett et al., 1998), decreases tyrosine hydroxylase (TH) activity (Haughey et al., 1999), and reduces both dopamine transporter and vesicular monoamine transporter levels at the membrane (Brown et al., 2000; Baucum et al., 2004). Our laboratory and others have shown that acutely applied amphetamines (1-3 $\mathrm{min}$ ) increases the firing activity of dopamine neurons (Ingram et al., 2002; Saha et al., 2014). Dopamine transporter activity and different ionic currents involved in action potentials (APs), such as L-type calcium current (Shibasaki et al., 2010), outward potassium current (Lin et al., 2010), and inwardly rectifying potassium current (Sharpe et al., 2015), are thought to be directly or indirectly associated with METH regulation of electrical properties of neurons, albeit with a mechanism that is less understood in dopamine neurons. 
Potassium $\left(\mathrm{K}^{+}\right)$channels, which comprise one of the most diverse classes of ion channels, regulate neuronal excitability in a variety of ways (Hille, 2001). Large-conductance $\mathrm{Ca}^{2+}$-activated potassium channels (KCa1.1, BK, MaxiK) play important roles in controlling neuronal excitability (Shao et al., 1999; Faber and Sah, 2002; Lin et al., 2014). BK channels have been shown to mediate a link between intracellular signaling pathways and electrical signals in the neurons through a feedback regulation countering increases in intracellular $\mathrm{Ca}^{2+}\left(\left[\mathrm{Ca}^{2+}\right]_{\mathrm{i}}\right)$ and membrane depolarization (Vergara et al., 1998; Latorre and Brauchi, 2006; Salkoff et al., 2006). BK channels shape neuronal activity in a number of ways, including AP termination (Lovell and McCobb, 2001), modifying firing frequency and spike frequency adaptation (Lin et al., 2014), and terminating bursting or bistable firing (Kiehn and Harris-Warrick, 1992; Lara et al., 1999). While BK channels are normally regarded as inhibitory (i.e., able to reduce neuronal excitability), numerous studies support the idea that suppression of BK-channel activity reduces neuronal excitability (Brenner et al., 2005; Gu et al., 2007; Lin et al., 2014). For example, activation of BK channels has been shown to enhance the excitability of adrenal chromaffin cells (Solaro et al., 1995; Lovell and McCobb, 2001), CA1 hippocampal pyramidal cells (Gu et al., 2007), and parasympathetic cardiac motoneurons in the nucleus ambiguus (Lin et al., 2014). Similarly, enhancement of BKchannel currents has been linked to neuronal hyperexcitability and epilepsy in cortical neurons (Brenner et al., 2005; Lorenz et al., 2007; Shruti et al., 2008; Wang et al., 2009).

METH has been shown to increase protein levels of the L-type calcium channel $\mathrm{Ca}_{\mathrm{v}} 1.2$ and $\mathrm{Ca}_{\mathrm{v}} 1.3$ in the frontal cortex and limbic forebrain neurons (Shibasaki et al., 2010), leading to increased intracellular $\mathrm{Ca}^{2+}$ levels (Uramura et al., 2000). Moreover, METH-induced inward $\mathrm{Na}^{+}$current via the dopamine transporter has been shown to depolarize dopamine neurons (Fischer and Cho, 1979; Stephans and Yamamoto, 1995; Saha et al., 2014). Therefore, METH stimulation of dopamine neurotransmission and thus behavioral responses might be in part due to METH regulation of the excitability of dopamine neurons by altering the activity of other channels, such as BK channels. In this study, we examined METH regulation of spontaneous spike activity, AP properties, and their potential association with BK channelmediated currents in midbrain dopamine neurons.

\section{Materials and Methods}

Animals

Midbrain neuronal cultures were obtained from RFP::TH mice (obtained from Dr. McMahon, Vanderbilt University), a transgenic mouse strain where the dopamine neurons are rendered fluorescent (Zhang et al., 2004). Briefly, the TH promoter-driven red fluorescent protein (RFP) transgene $(T H:: R F P)$ was constructed by ligating a $4.5 \mathrm{~kb}$ HindIII/EcoRI fragment of the rat TH promoter with DsRed2-1 (Clontech). Mice were housed in the animal care facilities at the University of Florida in accordance with Institutional Animal Care and Use Committee, under guidelines established by National Institutes of Health. Food and water were available ad libitum in the home cage. The room was maintained under $12 \mathrm{~h}$ light/dark cycle.

Neuronal and green fluorescent protein- $\alpha$-HEK293 cell culture Mouse midbrain dopamine neurons from $0-2$-d-old pups of either sex were isolated and incubated in a dissociation medium containing the following (in mM): $116 \mathrm{NaCl}, 5.4 \mathrm{KCl}, 26 \mathrm{NaHCO}_{3}, 25$ glucose, 2 $\mathrm{NaH}_{2} \mathrm{PO}_{4}, 1 \mathrm{MgSO}_{4}, 1.3$ cysteine, 0.5 EDTA, 0.5 kynurenate containing 20 units/ml papain at $34-36^{\circ} \mathrm{C}$ under continuous oxygenation for $2 \mathrm{~h}$. Tissue was then triturated with a fire-polished Pasteur pipette in glial medium containing the following: $50 \%$ minimum essential medium; $38.5 \%$ heat-inactivated fetal bovine serum; $7.7 \%$ penicillin/streptomy- cin; $2.9 \%$ D-glucose $\left(45 \%\right.$ solution in $\left.\mathrm{H}_{2} \mathrm{O}\right)$, and $0.9 \%$ glutamine $(200$ $\mathrm{mm})$. Dissociated cells were pelleted by centrifugation at $500 \times \mathrm{g}$ for 10 min and resuspended in glial medium. Cells were plated on $12 \mathrm{~mm}$ round coverslips coated with $100 \mu \mathrm{g} / \mathrm{ml}$ poly-L-lysine and $5 \mu \mathrm{g} / \mathrm{ml}$ laminin in $35 \times 10 \mathrm{~mm}$ tissue culture Petri dishes. One hour after plating, the medium was changed to neuronal medium containing the following: $2 \%$ minimum essential medium, 75\% Ham's F12 medium, 19\% heatinactivated horse serum, $2 \%$ heat-inactivated fetal bovine serum, $1.56 \%$ D-glucose ( $45 \%$ solution in $\left.\mathrm{H}_{2} \mathrm{O}\right), 0.04 \%$ insulin $(0.025 \mathrm{~g} / \mathrm{ml})$, and $0.4 \%$ apotransferrin $(50 \mathrm{mg} / \mathrm{ml})$. Neuronal medium was conditioned overnight on cultured glia. The conditioned neuronal medium was supplemented with $1 \mathrm{ng} / \mathrm{ml}$ glial cell line-derived neurotrophic factor and 500 $\mu \mathrm{M}$ kynurenate and filter-sterilized before it was added to the neuronal cultures.

HEK293 cells stably expressing green fluorescent protein (GFP)- $\alpha$ subunits were a generous gift from Dr. Robert Brenner, University of Texas Health Science Center at San Antonio. The cell culture and maintenance have been described previously (Goodwin et al., 2009; Saha et al., 2014).

\section{Electrophysiological recordings}

Whole-cell recordings. Spontaneous firing activity of midbrain dopamine neurons was examined via whole-cell current-clamp recordings. The neurons were continuously perfused with artificial CSF (aCSF) containing the following (in mM): $126 \mathrm{NaCl}, 2.5 \mathrm{KCl}, 2 \mathrm{CaCl}_{2}, 26 \mathrm{NaHCO}_{3}, 1.25$ $\mathrm{NaH}_{2} \mathrm{PO}_{4}, 2 \mathrm{MgSO}_{4}$, and 10 dextrose, equilibrated with $95 \% \mathrm{O}_{2}-5 \%$ $\mathrm{CO}_{2} ; \mathrm{pH}$ was adjusted to 7.4. Patch electrodes were fabricated from borosilicate glass ( $1.5 \mathrm{~mm}$ outer diameter; World Precision Instruments) with the P-2000 puller (Sutter Instruments). The tip resistance was in the range of 3-5 $\mathrm{M} \Omega$. The electrodes were filled with a pipette solution containing the following (in $\mathrm{mm}$ ): 120 potassium-gluconate, $20 \mathrm{KCl}, 2$ $\mathrm{MgCl}_{2}, 10$ HEPES, 0.1 EGTA, 2 ATP, and $0.25 \mathrm{GTP}$, with $\mathrm{pH}$ adjusted to 7.25 with $\mathrm{KOH}$. Unless indicated, all experiments were performed in the presence of dopamine $\mathrm{D}_{1}$ receptor antagonist $\mathrm{SCH} 23390(1 \mu \mathrm{M})$ and $\mathrm{D}_{2}$ receptor antagonist sulpiride ( $1 \mu \mathrm{M}$; Ingram et al., 2002) in the aCSF to block dopamine $\mathrm{D}_{1}$ and $\mathrm{D}_{2}$ receptors. All experiments were performed at $37^{\circ} \mathrm{C}$. To standardize AP recordings, neurons were held at their resting membrane potential (see below) by DC application through the recording electrode. APs were recorded if the following criteria were met: a resting membrane potential of $<-35 \mathrm{mV}$ and an AP peak amplitude of $>60 \mathrm{mV}$. AP half-width was measured as the spike width at the halfmaximal voltage using Clampfit 10 software (Axon Instruments). Since afterhyperpolarization (AHP) peaked at $\sim 10 \mathrm{~ms}$ from the beginning of the $\mathrm{AP}$, the AHP amplitudes were measured at $10 \mathrm{~ms}$. Steady-state basal activity was recorded for 2-3 min before bath application of the drug. For experiments involving drug application, each coverslip was used for only one recording. The spontaneous spike activity of midbrain dopamine neurons was obtained by averaging $1 \mathrm{~min}$ interval activities at baseline (before METH treatment) and after 7-10 min of METH. The paxilline modulation of spontaneous spike activity was measured after $4-5 \mathrm{~min}$ of drug exposure.

To record the outward currents, cells were perfused with aCSF solution as described above. Tetrodotoxin (TTX) and 4-aminopyridine (4AP) were included in the recording solution unless otherwise indicated. TTX $(0.0005 \mathrm{~mm})$ was used to block the voltage-dependent $\mathrm{Na}^{+}$channels and a low concentration of 4-AP (1 mM) was used to reduce voltagegated $\mathrm{K}^{+}$currents and to unmask the $\mathrm{Ca}^{2+}$ dependence of $\mathrm{K}^{+}$currents. Outward currents were evoked by a series of $200 \mathrm{~ms}$ depolarizing steps from -90 to $+50 \mathrm{mV}$ in $10 \mathrm{mV}$ increments. To avoid possible interference between responses, the depolarizing voltage steps were delivered every $5 \mathrm{~s}$. Data were obtained in 1-3 min intervals while the patches were held at $-65 \mathrm{mV}$. The series resistances were in the range of 5-10 $\mathrm{M} \Omega$ (typically $5 \mathrm{M} \Omega$ ) and were compensated $60 \%$ on-line. Membrane potential measurements were not corrected for the liquid junction potential $(\sim 15 \mathrm{mV})$. Leak currents were subtracted using a standard $\mathrm{P} / 4$ protocol. Before seals ( $5 \mathrm{G} \Omega$ ) were made on cells, offset potentials were nulled. Capacitance subtraction was used in all recordings. To determine current density $(\mathrm{pA} / \mathrm{pF})$, the peak current value of the steady-state current at 180 $\mathrm{ms}$ was divided by the membrane capacitance from each recorded cell. Mean current density was plotted against membrane potential $(I-V)$ and was fitted by the Boltzmann equation: $I=I_{\min }+\left(I_{\max }-I_{\min }\right) /[1+$ 
$\left.\exp -\kappa\left(V-V_{1 / 2}\right)\right]$, where $I$ is the current, $I_{\max }$ is the maximum current, $I_{\min }$ is the minimum current, $\kappa$ is a slope factor, and $V_{1 / 2}$ is the midpoint potential.

Single-channel recordings in dopamine neurons. Single-channel currents were recorded in outside-out patch configurations. Electrodes were pulled to a final tip resistance of 2-3 M $\Omega$ and filled with the internal solution as described above. To identify single BK channels in outsideout patches, the extracellular face of the channel was perfused with aCSF containing $2 \mathrm{mM} \mathrm{Ca}^{2+}$, and the cytoplasmic face was in the pipette internal solution with $0 \mathrm{~mm} \mathrm{Ca}^{2+}$. When multiple channel types were observed in a patch, BK currents were distinguished by the following characteristics: (1) presence of outward currents, (2) amplitudes $>10 \mathrm{pA}$ at $80 \mathrm{mV}$, (3) voltage regulation of outward current, and (4) paxilline sensitivity. For all single-channel recordings, the current was low-pass filtered at $1 \mathrm{kHz}$ and acquired at a sampling rate of $20 \mathrm{kHz}$ using a Digidata 1300 analog-to-digital converter (Molecular Devices) and the Clampex acquisition program of pCLAMP (version 10, Molecular Devices).

Recording from HEK cells expressing GFP- $\alpha$ subunits. HEK293-GFP- $\alpha$ subunit cells were cultured as described previously (Goodwin et al., 2009; Wang et al., 2009; Saha et al., 2014). The cells were plated on glass coverslips (Electron Microscopy Sciences). GFP expression was used to identify $\alpha$ subunit-expressing cells. Electrophysiology experiments were performed $3 \mathrm{~d}$ after plating the cells. Macropatch recordings were performed using the excised inside-out patch-clamp configuration at 22$23^{\circ} \mathrm{C}$. Patch pipettes were pulled to a final tip resistance of $1.5-3 \mathrm{M} \Omega$ and filled with the internal solution. The electrode solution was composed of the following (in mM): $20 \mathrm{HEPES}, 140 \mathrm{KMeSO}_{3}, 2 \mathrm{KCl}$, and $2 \mathrm{MgCl}_{2}, \mathrm{pH}$ 7.2. The bath solution was composed of a $\mathrm{pH} 7.2$ solution containing the following (in mM): $20 \mathrm{HEPES}, 140 \mathrm{KMeSO}_{3}$, and $2 \mathrm{KCl}$. Intracellular $\mathrm{Ca}^{2+}$ was buffered with $5 \mathrm{~mm} \mathrm{~N}$-(2-hydroxyethyl) ethylenediamine tracetic acid to give the required $10 \mu \mathrm{M}$ free $\left[\mathrm{Ca}^{2+}\right]$ concentration calculated using the Maxchelator program (Winmaxchelator software; Dr. Chris Patton, Stanford University, Pacific Grove, CA). Recordings and data acquisition were described above (see Single-channel recordings in dopamine neurons).

\section{Immunofluorescence staining and confocal imaging}

Midbrain dopamine neurons were grown on glass coverslips and treated with vehicle or $10 \mu \mathrm{M}$ METH for 15 or $30 \mathrm{~min}$. The cells were then washed with HBSS solution (Life Technologies) and fixed with freshly prepared $3.7 \%$ paraformaldehyde (Electron Microscopy Sciences) for 20 min at room temperature and washed twice with PBS solution. Neurons were then incubated with $4 \mathrm{mg} / \mathrm{ml}$ Alexa 555-conjugated cholera toxin subunit $\mathrm{B}$ for $30 \mathrm{~min}$ at $4^{\circ} \mathrm{C}$ followed by three $20 \mathrm{~min}$ washes. For immunolabeling of $\alpha$ subunits of BK channels, the cells were then permeabilized as described by Misonou et al. (2006). Washes, blocking, and incubation with primary and secondary antibodies were performed in cell-collection chambers on the stage of an orbital shaker. The neurons were incubated in blocking solution containing $10 \%$ normal goat serum (Lampire Biological Laboratories) and 0.5\% Triton X-100 in PBS (Sigma-Aldrich) at room temperature for $1 \mathrm{~h}$. The neurons were then washed three times with PBS and incubated with a solution containing primary antibody (anti-Slo1/BK $\alpha$ potassium channel antibody; 1:1000), 0.1\% Triton $\mathrm{X}-100$, and $5 \%$ normal goat serum at $4^{\circ} \mathrm{C}$ overnight. The primary antibody anti-Slo1/BK $\alpha$ potassium channel was purchased from NeuroMab (ID: AB 2249538). On the following day, the primary antibody was removed and cells were subjected to three 20 min washes before addition of Alexa Fluor 488-conjugated secondary antibody (Life Technologies) diluted at 1:200-500 in PBS. Cells were incubated in secondary antibody for $1 \mathrm{~h}$ in the dark at room temperature followed by three $20 \mathrm{~min}$ washes. Coverslips were then mounted on the Superfrost Excell Microscope Slides (VWR) using Flouromount-G (SouthernBiotech). Slides were stored in the dark at $4^{\circ} \mathrm{C}$ until imaging. Confocal images were collected using a Nikon A1 laser-scanning confocal microscope. Excitation wavelengths were set at 488 and $555 \mathrm{~nm}$ for the respective fluorescent markers. Images were acquired using $488 \mathrm{~nm}$ excitation with a $514 \mathrm{~nm}$ long pass filter and $555 \mathrm{~nm}$ excitation with a $561 \mathrm{~nm}$ long pass filter. Images were taken using a $60 \times$ Nikon objective with a 1.40 numerical aperture.
Table 1. Chemicals reagents and drugs for primary neuronal culture

\begin{tabular}{|c|c|c|}
\hline Chemicals & Concentration & Supplier; catalog number \\
\hline $\mathrm{NaCl}$ & $116 \mathrm{~mm}$ & Sigma-Aldrich; S7653 \\
\hline $\mathrm{KCl}$ & $5.4 \mathrm{~mm}$ & Sigma-Aldrich; P9541 \\
\hline $\mathrm{NaHCO}_{3}$ & $26 \mathrm{~mm}$ & Sigma-Aldrich; S5761 \\
\hline$D-(+)$-glucose & $25 \mathrm{~mm}$ & Sigma-Aldrich; G8270 \\
\hline $\mathrm{NaH}_{2} \mathrm{PO}_{4}$ & $2 \mathrm{~mm}$ & Sigma-Aldrich; 71505 \\
\hline $\mathrm{MgSO}_{4}$ & $1 \mathrm{~mm}$ & Sigma-Aldrich; m7506 \\
\hline Cysteine & $1.3 \mathrm{~mm}$ & Sigma-Aldrich; C6645 \\
\hline EDTA & $0.5 \mathrm{~mm}$ & Sigma-Aldrich; E9884 \\
\hline Kynurenate & $0.5 \mathrm{~mm}$ & Sigma-Aldrich; K3375 \\
\hline Papain & $20 \mathrm{U} / \mathrm{ml}$ & Worthington; LS003126 \\
\hline Penicillin/streptomycin & $7.70 \%$ & Sigma-Aldrich; P4333 \\
\hline L-glutamine & $0.90 \%$ & Sigma-Aldrich; $59202 C$ \\
\hline Poly---lysine & $100 \mu \mathrm{g} / \mathrm{ml}$ & Sigma-Aldrich; P1399 \\
\hline Laminin & $5 \mu \mathrm{g} / \mathrm{ml}$ & Sigma-Aldrich; L2020 \\
\hline Insulin & $0.025 \mathrm{~g} / \mathrm{ml}$ & Sigma-Aldrich; I2643 \\
\hline Apotransferrin & $50 \mathrm{ml} / \mathrm{ml}$ & Sigma-Aldrich; T0178 \\
\hline GDNF & $1 \mathrm{ng} / \mathrm{ml}$ & Sigma-Aldrich; SRP3200 \\
\hline
\end{tabular}

Table 2. Antibodies for immunofluorescence staining and Western blot

\begin{tabular}{llll}
\hline Antibody & Host species & Dilution & Supplier; catalog number \\
\hline Slo1 maxi-K + channel & Mouse (monoclonal) & $1: 1000$ & NeuroMab; ID: AB 2249538 \\
Alexa Fluor 488 & Anti-mouse lgG $(\mathrm{H}+\mathrm{L})$ & $1: 500$ & Life Technologies; A-11029 \\
Cholera toxin subunit B & & $4 \mu \mathrm{g} / \mathrm{ml}$ & Life Technologies; (-34776 \\
\hline
\end{tabular}

The intensity correlation quotient (ICQ) analysis was completed as described by Li et al. (2004). The ICQ provides a single value indication that can be used for statistical comparison. Typically, with $N$ (number of pixels) $>5$ ROIs, a mean ICQ value of -0.05 to +0.05 indicates random staining, +0.05 to +0.10 indicates a moderate covariance, and $>0.1$ indicates a strong covariance. A high staining overlap in the absence of covariance will not generate a high ICQ value. In fact, in the extreme case where all pixels are stained equally by the two dyes, the ICQ value will be 0 , reflecting a lack of covariance. ICQ analysis was performed via an automated graphic plugin (Image Correlation Analysis V8-13) for the public domain image analysis software ImageJ (Wayne Rasband, Research Services Branch, National Institutes of Mental Health, National Institutes of Health, Bethesda, MD).

\section{Total internal reflection fluorescence microscopy}

For these experiments, HEK293 cells expressing GFP- $\alpha$ subunits were plated onto $35 \mathrm{~mm}$ glass-bottom dishes (No. 1 thickness) to $60-80 \%$ confluence. A Nikon Ti Eclipse (Nikon) inverted microscope equipped with a multiline solid-state laser source $(470,514,561 \mathrm{~nm})$ was used for all total internal reflection fluorescence (TIRF) microscopy imaging. Lasers were guided through a $60 \times 1.4$ numerical aperture objective. Images were detected digitally using a CCD camera. Image exposure time was coupled with stimulation duration at $100 \mathrm{~ms}$ and laser intensity was maintained at $40 \%$. For quantification of fluorescence intensity at the cell surface, experimenter-defined ROIs were created for each cell to exclude both cell membrane overlap between adjacent cells and measurement of intensity at the peripheral edges of cells. Background fluorescence was subtracted from all images. Mean intensity over time for each cell ROI was recorded continuously before and after the application of $10 \mu \mathrm{M}$ METH, $0.1 \mu \mathrm{M} \beta$-phorbol 12-myristate 13-acetate (PMA), or $1 \mu \mathrm{M}$ bisindolylmaleimide I (BIM-I) to the bath solution. All imaging were performed in the isotonic, isosmotic external solution described above. The baseline fluorescent intensity is defined as the average fluorescent intensity $5 \mathrm{~min}$ before drug application. All values were normalized to the baseline fluorescent intensity. Single-count elementary sequential smoothing was applied for image presentation only and not for analysis. Bleaching at each experimental time point was determined by the amount of decreased fluorescence intensity in untreated cells.

\section{Western blot}

For Western blot analysis, midbrain and striatal tissue from adult wildtype C57BL/6 mice was harvested and homogenized in RIPA buffer con- 
Table 3. Chemicals reagents and drugs for electrophysiological and TIRF recordings

\begin{tabular}{lcl}
\hline Chemicals & Concentration (mm) & Supplier and catalog number \\
\hline $\mathrm{NaCl}$ & 126 & Sigma-Aldrich, S7653 \\
$\mathrm{KCl}$ & 2.5 & Sigma-Aldrich, P9541 \\
$\mathrm{CaC}_{\mathrm{I} 2}$ & 2 & sigma-Aldrich, 223506 \\
$\mathrm{NaHCO}_{3}$ & 26 & Sigma-Aldrich, S5761 \\
$\mathrm{NaH}_{2} \mathrm{PO}_{4}$ & 1.25 & Sigma-Aldrich, 71505 \\
$\mathrm{MgSO}_{4}$ & 2 & Sigma-Aldrich, M7506 \\
Dextrose & 10 & Sigma-Aldrich, D9434 \\
Potassium gluconate & 120 & Sigma-Aldrich, P1847 \\
$\mathrm{MgCl}_{2}$ & 2 & Sigma-Aldrich, M8266 \\
HEPES & 10 & Sigma-Aldrich, H3375 \\
EGTA & 0.1 & Sigma-Aldrich, E3889 \\
$\mathrm{ATPNa}_{2}$ & 2 & Sigma-Aldrich, A2383 \\
$\mathrm{GTPNa}$ & 0.25 & Sigma-Aldrich, G8877 \\
SCH23390 & 0.001 & Sigma-Aldrich, D054 \\
Sulpiride & 0.001 & Sigma-Aldrich, S8010 \\
Tetrodotoxin & 0.0005 & Cayman, 14964 \\
4-Aminopyridine & 1 & Sigma-Aldrich, 275875 \\
Methamphetamine & 0.01 & Sigma-Aldrich, M8750 \\
Paxilline & 0.01 & Tocris, 2006 \\
NS 1619 & 0.01 & Sigma-Aldrich, N170 \\
PMA & 0.0001 & Sigma-Aldrich, P8139 \\
Bisindolylmaleimide I & 0.001 & EMD Millipore, 203291 \\
\hline & & \\
\hline & &
\end{tabular}

taining protein/phosphatase inhibitors (Thermo Pierce). Homogenized tissue was incubated in lysis buffer for $30 \mathrm{~min}$ at $4^{\circ} \mathrm{C}$. Soluble protein was isolated by centrifugation at $10,000 \mathrm{rpm}$ for $10 \mathrm{~min}$ at $4^{\circ} \mathrm{C}$ and denatured by incubation with Laemmli sample buffer (Bio-Rad) at $65^{\circ} \mathrm{C}$ for $15 \mathrm{~min}$. Samples were run on $10 \%$ acrylamide SDS-PAGE gels and transferred to PVDF membranes. Membranes were incubated with mouse anti-Slo1 maxi- $\mathrm{K}^{+}$channel antibody at $1: 1000$ overnight at $4^{\circ} \mathrm{C}$. Membranes were then washed and incubated with horseradish peroxidase-conjugated secondary antibodies for $1 \mathrm{~h}$ at room temperature. After washes, proteins were visualized using SuperSignal West Pico Chemiluminescent Substrate (Thermo Fisher Scientific).

Drugs and reagents. The drugs and reagents used in this study were purchased from Sigma-Aldrich. Anti-Slo1/BK $\alpha$ potassium channel was purchased from NeuroMab (ID: AB 2249538); secondary antibodies (fluorophore-conjugated) and cholera toxin subunit B were purchased from Thermo Fisher Scientific (Life Technologies). All other reagents and supplies were purchased as described above.

Chemicals, reagents, and drugs used for primary neuronal culture are listed in Table 1. Antibodies used for immunofluorescence staining and Western blot analysis are listed in Table 2. The catalog number of the reagents and drugs used for electrophysiology and microscopy experiments are listed in Table 3.

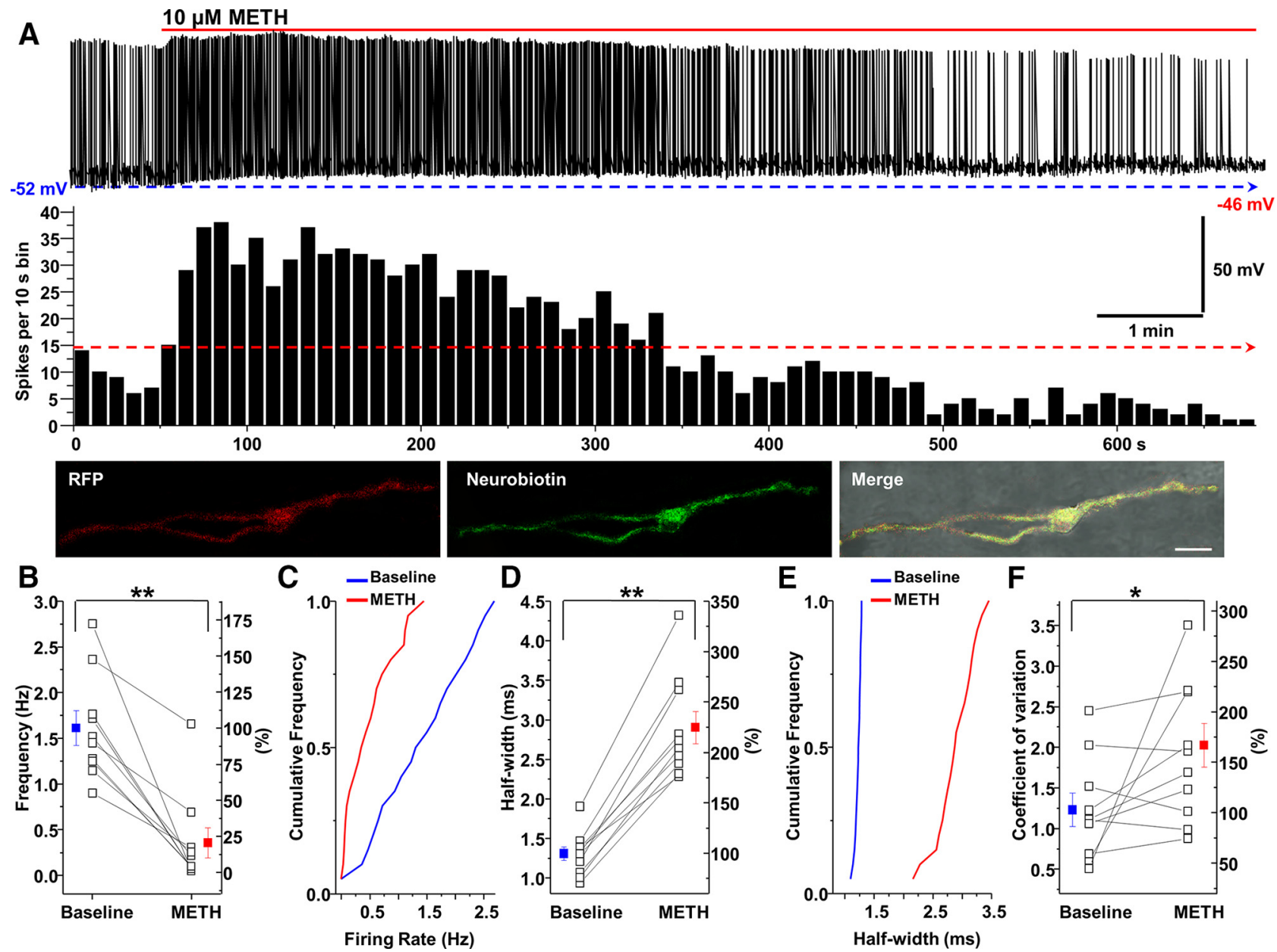

Figure 1. METH produces a biphasic effect on the spontaneous firing activity of midbrain dopaminergic neurons. $A$, Top, Representative trace of a spontaneously active dopamine neuron before (baseline, no drug) and after application of $10 \mu \mathrm{M}$ METH. Middle, Rate histogram of the trace shown in the top panel, in which each bar represents the total spikes within each $10 \mathrm{~s}$ interval. Bottom, Representative image of RFP::TH-labeled (left) and neurobiotin-labeled (middle) neurons. Merged image is shown in the right panel (scale bar, $20 \mu \mathrm{m}$ ). $\boldsymbol{B}, \boldsymbol{C}$, Data are mean \pm SEM; the spontaneous firing rate is decreased after prolonged ( $>4 \mathrm{~min}$ ) METH treatment. $D, E$, Mean \pm SEM; METH significantly increased the spike half-width. $F$, Mean \pm SEM; interspike intervals were calculated over $1 \mathrm{~min}$ of spontaneous firing activity (baseline, no drug). METH-treated neurons exhibited larger coefficients of variation of the interspike interval compared with the baseline, suggesting METH exposure produced a variable firing pattern. $\ln \boldsymbol{B}, \boldsymbol{D}$, and $\boldsymbol{F}$, left $y$-axis shows absolute values, right $y$-axis shows normalized values. ${ }^{*} p<0.05$; ${ }^{* *} p<0.01$ ( $n=10$ per group). 
A

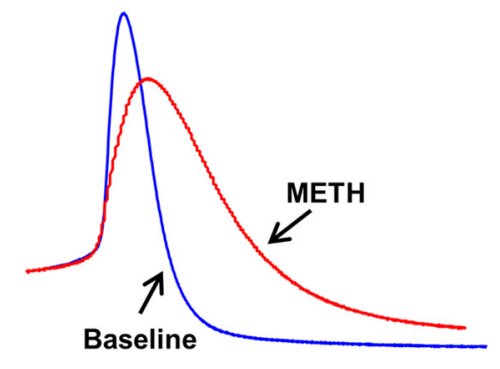

B

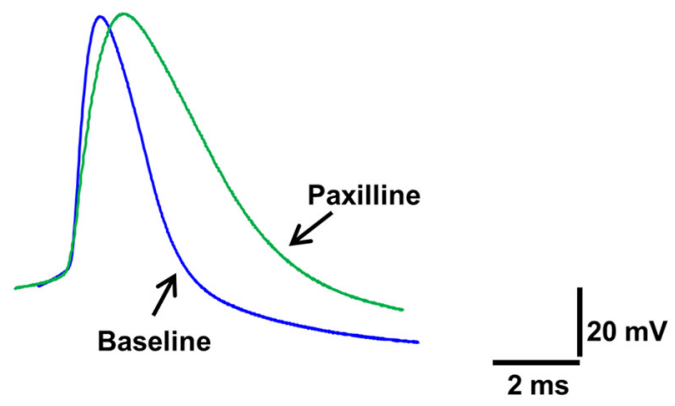

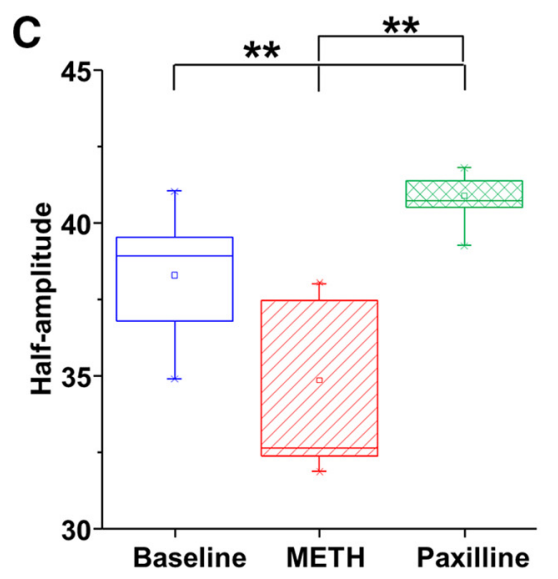
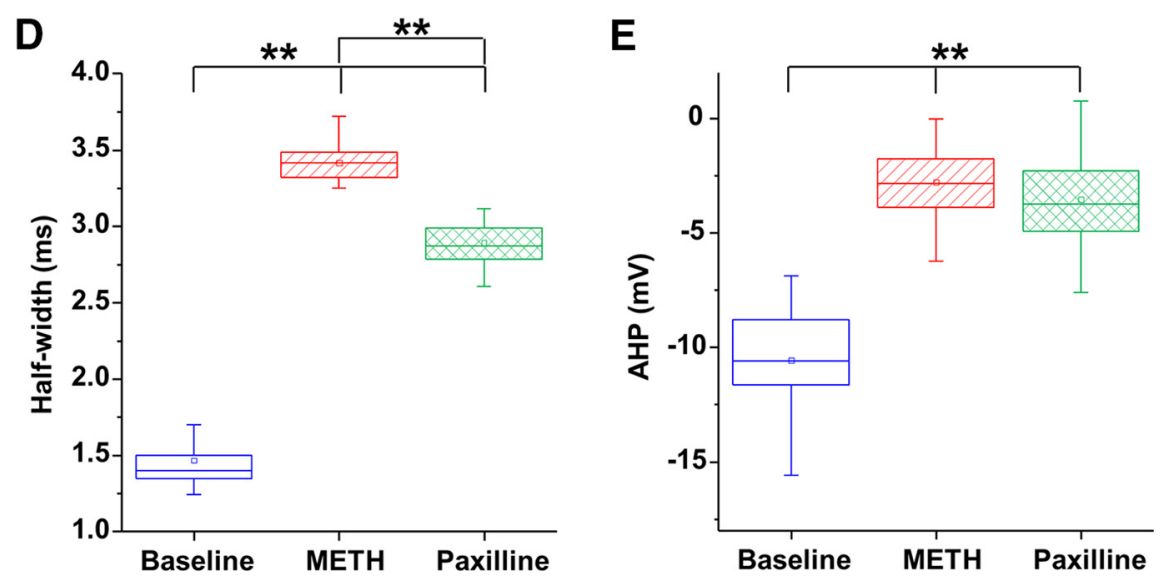

Figure 2. Single-spike analyses suggest that METH and paxilline modulate the repolarization and AHP. $A$, Representative traces of single AP at baseline (blue trace) and following METH treatment (10 $\mu \mathrm{m}$, red trace). $\boldsymbol{B}$, Representative traces of single APs at baseline (blue trace) and following blockade of BK channels with paxilline (10 $\mu \mathrm{m}$, green trace). C, Data are mean \pm SEM; while METH treatment decreased the half-amplitude of APs, paxilline increased the half-amplitude of APs. D, Mean \pm SEM; compared with the baseline untreated condition, both METH and paxilline exposure broadened the spike half-width. $E$, Mean \pm SEM; METH or paxilline decreased the peak amplitude of AHP. Boxplot whiskers indicate maximum and minimum data points. ${ }^{* *} p<0.01(n=7$ or 8 per group).

\section{Data analysis}

The electrophysiology data were acquired using the ClampEx 10 software package (Molecular Devices). The data were analyzed off-line using pClamp 10. The nonparametric Kolmogorov-Smirnov test was used to compare cumulative distributions in situations where two groups being compared had unequal variances or were not normally distributed. $\mathrm{Cu}-$ mulative distribution differences for firing rate and half-width were evaluated using the Kolmogorov-Smirnov test with Clampfit 10 software. For all experiments, the data are presented as mean \pm SEM. $N$ denotes the number of neurons or cells for each experiment. Statistical significance was assessed using two-tailed Student's $t$ tests or one-way ANOVA. If ANOVA showed statistical significance, all pairwise post hoc analysis was performed using a Tukey's post hoc test. Differences were considered significant at $p<0.05\left({ }^{*}\right.$, significance $<0.05 ;{ }^{* *}$, significance $\left.<0.01\right)$. The coefficient of variation is a measure of the relative spread of the data. It is computed as the SD divided by the mean times $100 \%$.

\section{Results}

\section{Identification of dopamine neurons}

We used multiple complementary approaches to ensure the proper identification of dopamine neurons in our recordings. The dopaminergic neurons were identified in the following ways: (1) by expression of TH promoter-driven RFP, (2) morphologically by their large cell bodies with broad $2-5$ first-order processes, (3) electrophysiologically by their well characterized spontaneous firing frequency of $0.3-4 \mathrm{~Hz}$, and (4) by their previously described acute response to METH (Ingram et al., 2002; Branch and Beckstead, 2012; Saha et al., 2014). The recording pipettes were filled with internal solution (as described in Materials and Methods) plus neurobiotin. After the recordings, the neurons were subjected to immunolabeling for neurobiotin and
TH-RFP (Fig. 1A, bottom). A total of 232 midbrain dopamine neurons were recorded and analyzed for the experiments outlined below. The average input resistance was $320.5 \pm 22.5 \mathrm{M} \Omega$; the membrane time constant was $832.1 \pm 46.7 \mu \mathrm{s}$; and the membrane capacitance was $65.8 \pm 3.3 \mathrm{pF}$. All of the experiments were performed in the presence of $\mathrm{D}_{1}$ and $\mathrm{D}_{2}$ receptor blockers.

\section{METH produces a biphasic effect on the spontaneous firing activity of midbrain dopamine neurons}

Figure $1 A$ shows a representative example of spontaneous spike activity before and after METH application. Consistent with previous studies (Grace and Bunney, 1984; Tepper et al., 1987), the majority of the recorded dopamine neurons exhibited a mixture of single spikes and burst activity with an underlying "pacemaker-like" periodicity. Tonic irregular single-spike firing occurred at rates of 1-4 spikes per second; bursts of 3-8 spikes occurred at high frequencies of $\sim 10-20 \mathrm{~Hz}$ with a pause between subsequent bursts. The resting potential was defined as the baseline voltage at spike threshold. Bath application of METH produced a rapid but transient increase in the firing frequency, followed by a progressive decrease in the firing frequency within 4-10 $\min$ (Fig. 1A, top). While the membrane potential at baseline before drug application was $-51.1 \pm 1.7 \mathrm{mV}$, the membrane potential following $10 \mathrm{~min}$ of continuous METH treatment was $-44.2 \pm 2.4 \mathrm{mV}\left(t_{(18)}=-2.4, p<0.05\right.$, two-tailed Student's $t$ tests; $n=10$ ). This was accompanied by a $\sim 78 \%$ reduction in the mean firing rate, which was determined from the mean baseline value set at $100 \%$ (Fig. $1 B, C ; B: t_{(18)}=5.3, p<0.01$, twotailed Student's $t$ tests; $C: p<0.0001$, Kolmogorov-Smirnov test; 


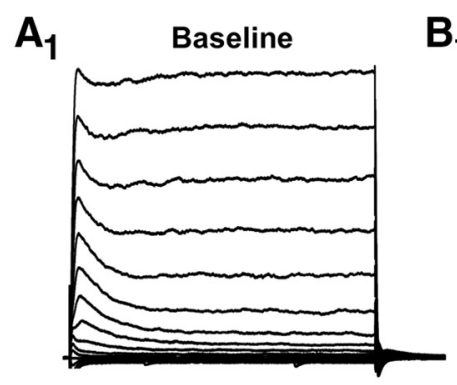

$B_{1}$ Baseline

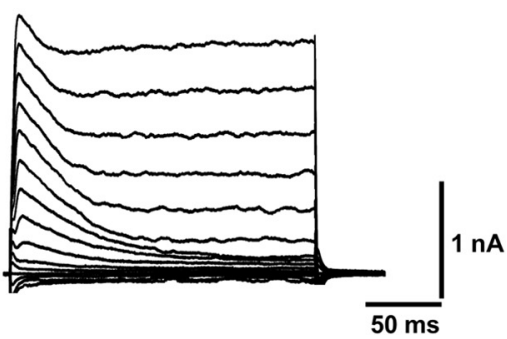

C
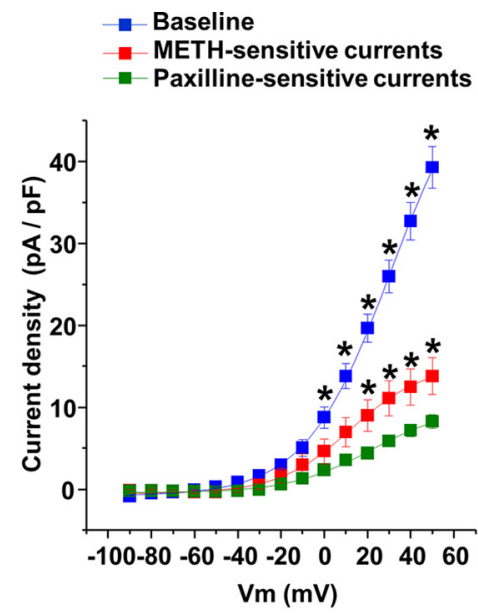

Baseline METH

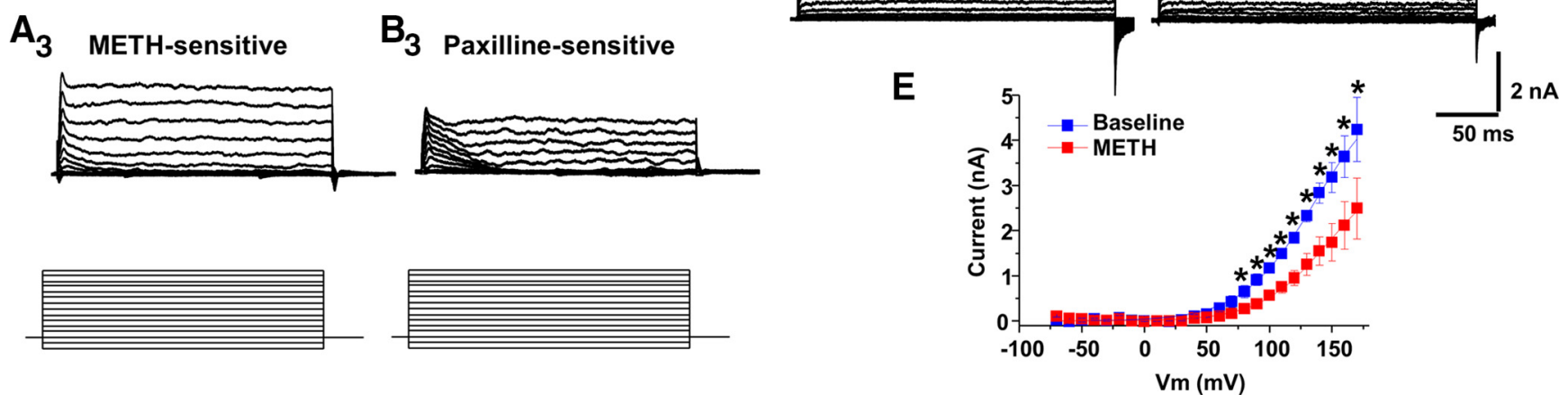

Figure 3. METH or paxilline inhibits $\mathrm{Ca}^{2+}$-activated $\mathrm{K}^{+}$(BK) channel-mediated outward currents. $\boldsymbol{A}_{1}, \boldsymbol{B}_{1}$, Families of outward currents were evoked by voltage steps from $-90 \mathrm{to}+50 \mathrm{mV}$ for $200 \mathrm{~ms}$ with $10 \mathrm{mV}$ increments every 5 from the holding potential of $-70 \mathrm{mV} . \boldsymbol{A}_{2}, \boldsymbol{B}_{2}$, Outward currents after METH (10 $\left.\mu \mathrm{M}\right)$ or paxilline $(10 \mu \mathrm{m})$ treatment. $\boldsymbol{A}_{3}, \boldsymbol{B}_{3}, \mathrm{METH}$-sensitive $\left(\boldsymbol{A}_{1}-\boldsymbol{A}_{2}\right)$ and paxilline-sensitive $\left(\boldsymbol{B}_{\boldsymbol{1}}-\boldsymbol{B}_{2}\right)$ currents. $\boldsymbol{C}$, Data are mean \pm SEM; from 0 to $+50 \mathrm{mV}$ membrane potential, the peak current at baseline was significantly larger than METH-sensitive or paxillinesensitive currents. From +20 to $+50 \mathrm{mV}$ membrane potentials, METH-sensitive currents were larger than paxilline-sensitive currents. $\boldsymbol{D}$, In cells expressing BK- $\alpha$ subunits, families of outward currents were evoked by voltage steps from -70 to $+170 \mathrm{mV}$ for $250 \mathrm{~ms}$ with $10 \mathrm{mV}$ increments every $5 \mathrm{~s}$ from the holding potential of $-70 \mathrm{mV}$, before and after METH administration. $E$, Mean \pm SEM; shows peak $I-V$ curves before (baseline) and after METH application. ${ }^{*} p<0.05$ ( $n=5,8$, or 11 per group).

$n=10)$. In addition, METH exposure broadened the spike halfwidth measured at the half-maximal voltage (Fig. $1 D, E ; D$ : $t_{(18)}=-7.2, p<0.01$, two-tailed Student's $t$ tests; $E: p<0.0001$, Kolmogorov-Smirnov test; $n=10$ ). Compared with baseline control, the coefficient of variation of the interspike interval was significantly increased by $66.6 \pm 2.4 \%$ after continuous METH application (10 min), suggesting that METH exposure produces a variable firing pattern (variable spike interval; Fig. $1 F$; METH: $2.03 \pm 0.27$; baseline: $1.23 \pm 0.21 ; t_{(18)}=-2.4, p<0.05$, twotailed Student's $t$ tests; $n=10$ ).

METH and paxilline blockade of BK channels regulate the repolarization and AHP of APs

Activation of BK channels has been shown to contribute to AP repolarization and AHP (Adams et al., 1982; Lancaster and Nicoll, 1987; Faber and Sah, 2002; Lin et al., 2014). Thus, to understand whether METH regulation of intrinsic firing behavior of dopamine neurons involves BK channel activity, we examined the influence of METH and a BK channel blocker paxilline on single spike amplitudes, repolarization, and AHP in spontaneously active dopamine neurons (Fig. $2 A, B$ ). We found while METH $(10 \mu \mathrm{M})$ decreased the half amplitude of APs and paxilline $(10 \mu \mathrm{M})$ increased the half amplitude of APs [Fig. $2 C ; F_{(2,52)}=$
44.3, $p<0.01$, one-way ANOVA followed by Tukey's test; $n$ : baseline, 7 neurons (17 spikes); METH, 8 neurons (20 spikes); paxilline, 7 neurons (18 spikes)], both METH and paxilline treatments significantly increased the mean half-widths of APs and decreased the amplitude of AHP [Fig. 2D,E; $D: F_{(2,55)}=777.9$, $p<0.01$, one-way ANOVA followed by Tukey's test; $n$ : baseline, 8 neurons (20 spikes); METH, 8 neurons (20 spikes); paxilline, 7 neurons (18 spikes); $E: F_{(2,102)}=163.8, p<0.01$, one-way ANOVA followed by Tukey's test, $n=7$ neurons ( 35 spikes)/ group)]. This suggests continuous METH exposure might have altered the activity of BK channels. Since blockade of BK channels by paxilline broadened the APs in dopamine neurons (Fig. $2 B, D)$, it is possible that the METH-induced increased in AP widths (Fig. $2 A, D$ ) is in part due to inhibition of BK channels. To test whether METH modulates BK channel-mediated currents, families of outward currents were evoked by $200 \mathrm{~ms}$ voltage steps ranging from -90 to $+50 \mathrm{mV}$ in $10 \mathrm{mV}$ increments from a holding potential of $-70 \mathrm{mV}$ (Fig. $3 A_{1}, B_{1}$ ). METH application (3 min) reduced outward currents (Fig. $3 A_{2}$ ). METH-sensitive outward currents (Fig. $3 A_{3}$ ) were obtained by subtracting the currents after METH application from the currents evoked before METH application (baseline). To isolate the BK channelsmediated outward currents, the paxilline-sensitive currents (Fig. 


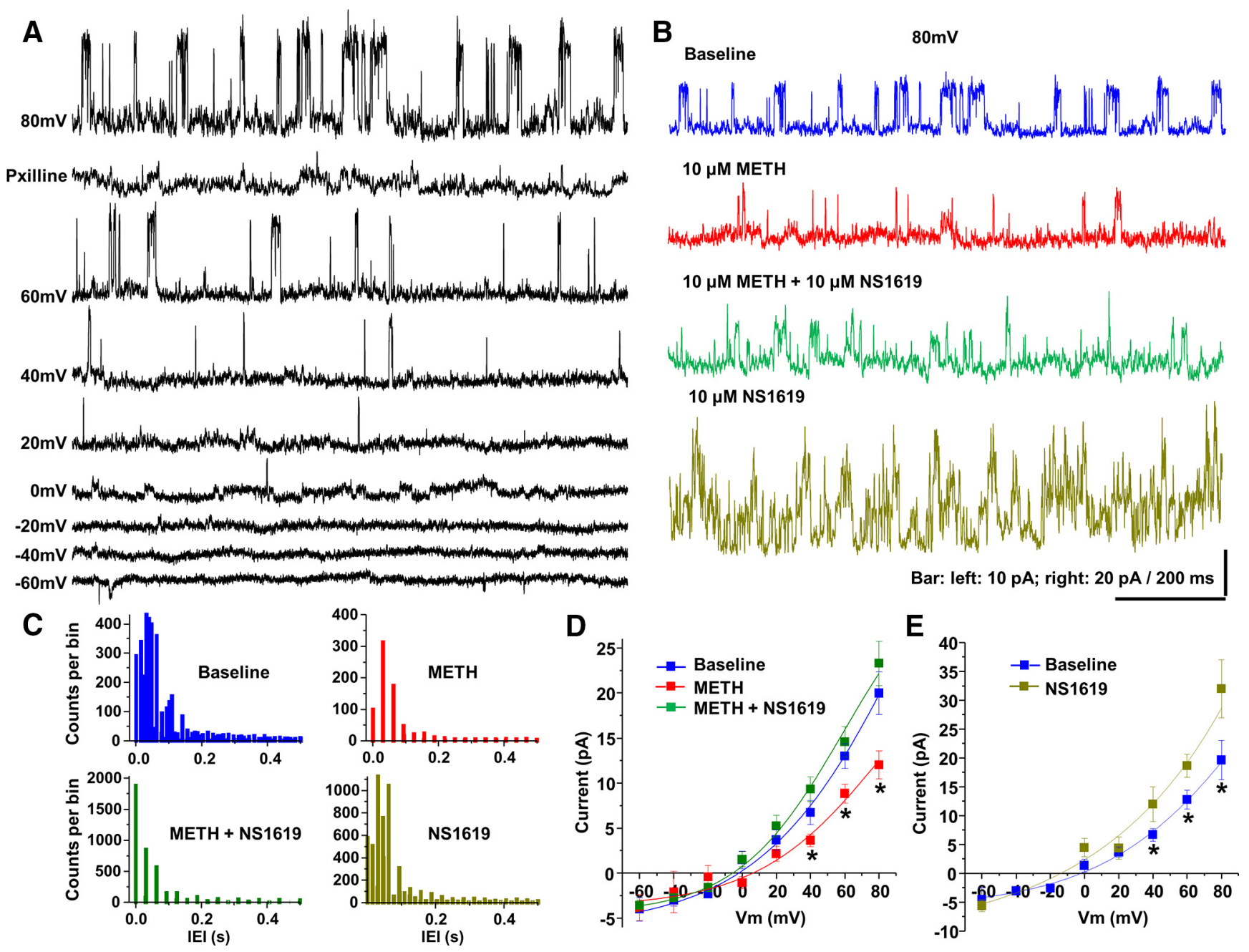

Figure 4. METH regulates the activity of large-conductance $\mathrm{Ca}^{2+}$-activated $\mathrm{K}^{+}(\mathrm{BK})$ channels. $A$, Identification of BK channels in midbrain dopamine neurons. Representative currents recorded from an outside-out patch of dopamine neurons at different holding potentials; unitary upward current deflections are visible at potentials $>+20 \mathrm{mV}$. Second trace from the top depicts paxilline blockade of unitary upward current deflections at $+80 \mathrm{mV}$. B, Representative currents recorded from outside-out patch of dopamine neurons held at $+80 \mathrm{mV}$ in the absence of METH (top), the presence of METH (second trace), the presence of METH plus NS1619 (an activator of BK channel; third trace), and the presence of NS1619 alone (fourth trace). C, Data are mean \pm SEM; interevent interval (IEl; $1 \mathrm{~ms} \mathrm{bin)} \mathrm{histograms} \mathrm{of} \mathrm{BK} \mathrm{currents} \mathrm{obtained} \mathrm{from} \mathrm{the} \mathrm{data} \mathrm{recorded} \mathrm{at} \mathrm{the} \mathrm{holding} \mathrm{potential} \mathrm{of}+80 \mathrm{mV}$ for $6 \mathrm{~s}$. The frequency of baseline BK currents as determined from IEls was significantly decreased after METH treatment, but significantly increased in the presence of METH plus NS1619. D, Mean \pm SEM; peak I-V curves were plotted against the membrane potential. The single-channel conductance generated by the linear fit in control condition was $209 \mathrm{pS}$. METH decreased the peak amplitude of unitary currents compared with control. NS1619 treatment attenuated the effect of METH on the unitary current amplitude. $E$, Mean \pm SEM; the activator of the BK channel, NS1619, alone increased the peak amplitude of unitary currents compared with control, the untreated condition. ${ }^{*} p<0.05$ ( $n=5,7,8,9$, or 10 per group).

$3 B_{3}$ ) were obtained by subtracting the currents after paxilline (Fig. $3 B_{2}$ ) from the outward currents before paxilline application (baseline). The current-voltage $(I-V)$ curves are shown in Figure 3C. Similar to METH and paxilline regulation of AP potential morphology, the $I-V$ curves for both METH and paxilline blockade of BK channels shared general similarities; nevertheless, they only point to the possibility of METH modulation of BK channelmediated currents in dopamine neurons. Therefore, we next asked whether METH affects the activity of the BK channel in HEK293 cells expressing GFP- $\alpha$ subunits of BK channel (Fig. $3 D, E)$. We used excised inside-out patches to record currents in response to test voltage steps. In the neurons, BK channels are colocalized with a $\mathrm{Ca}^{2+}$ source, i.e., they are very close to a calcium channel so that the local concentration of $\mathrm{Ca}^{2+}$ near BK channel is high (Fakler and Adelman, 2008; Cox, 2014). Since HEK cells do not provide a similar colocalized calcium source (unless they cotransfected a calcium channel), in excised insideout patch experiments, we used a buffered $\mathrm{Ca}^{2+}$ concentration of
$10 \mu \mathrm{M}\left[\mathrm{Ca}^{2+}\right]$ at the cytoplasmic side of the membrane. Figure $3 D$ shows representative $\mathrm{BK}$ currents in response to test voltage steps. Figure $3 E$ shows the $I-V$ curves. As shown in Figure $3 E$, METH decreased the peak BK channel-mediated currents. These results are consistent with the interpretation that METH reduces the activity of the BK channel by potentially targeting the poreforming $\alpha$ subunit of the BK channel.

Methamphetamine reduced BK unitary currents

To further examine METH regulation of BK currents in dopamine neurons, first we identified the unitary BK channel outward currents in outside-out excised patches of dopamine neurons $(n=8)$. As shown in Figure 4, the BK channels exhibited singlechannel unitary currents, had a large conductance, and at +80 $\mathrm{mV}$ predominantly existed in the open state (Fig. $4 A$, top trace). These single-channel currents were almost completely blocked by paxilline (Fig. $4 A$, second trace from top) and recovered after paxilline washout (data not shown). At and below $-20 \mathrm{mV}$, the 

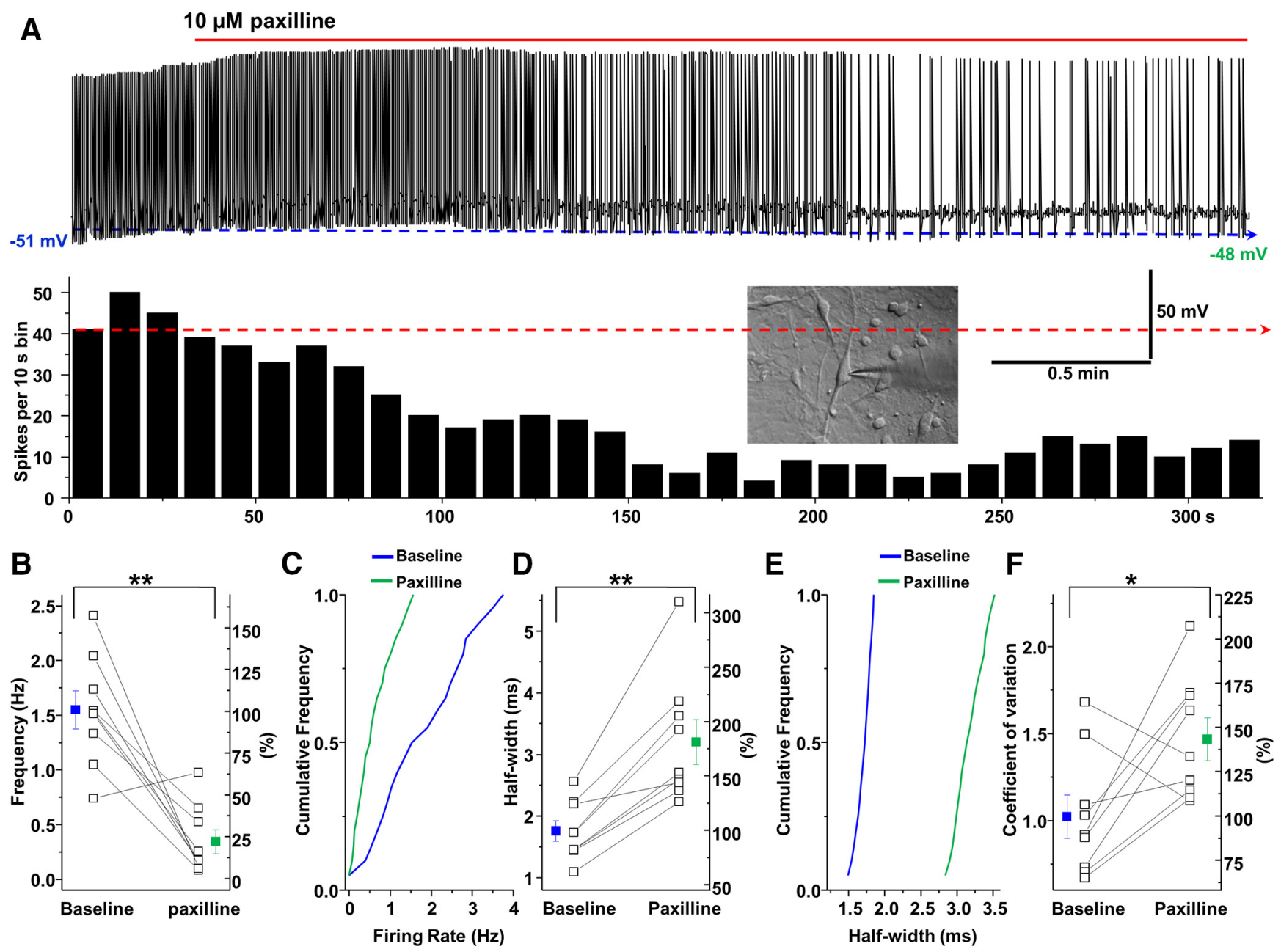

Figure 5. Paxilline decreases the spontaneous firing activity of dopamine neurons. $A$, Top, Representative trace from a spontaneously active dopamine neuron before and after application of paxilline $(10 \mu \mathrm{m})$. Bottom, A rate histogram from the above trace. $B, C$, Data are mean $\pm S E M$; analysis of the frequency of the spontaneous firing activity of dopamine neurons after blockade of $B K$ channels. $\boldsymbol{D}, \boldsymbol{E}$, Mean $\pm S E M$; blockade of BK channels increases the spike half-width. $\boldsymbol{F}$, Mean $\pm S E M$; interspike intervals were calculated over 1 min of firing activity. Compared with the baseline drug-free condition, blockade of $B K$ channels exhibited larger coefficients of variation of the interspike interval. $\ln \boldsymbol{B}, \boldsymbol{D}$, and $\boldsymbol{F}$, the left $y$-axis shows absolute values, and the right $y$-axis shows normalized values. ${ }^{*} p<0.05 ;{ }^{* *} p<0.01$ ( $n=9$ per group).

BK channels were mostly in a closed state. At $+20 \mathrm{mV}$, macroscopic unitary upward deflections were detected, where their amplitude increased at depolarized potentials of $+40,+60$, and +80 $\mathrm{mV}$. We used these experimental settings to study METH regulation of BK channel activity in outside-out excised patches after METH treatment. Figure $4 B$ shows unitary BK currents recorded at a holding potential of $+80 \mathrm{mV}$ at baseline; after application of METH; after application of NS1619, a BK channel opener, followed by METH; or after application of NS1619 alone. The frequency of baseline unitary BK currents (determined from interevent intervals) was significantly decreased after METH administration (Fig. $4 C ; p<0.0001$, Kolmogorov-Smirnov test; $n=8$ vs 10). Application of NS1619 significantly increased the frequency of BK currents when coadministered with METH (Fig. $4 C$, bottom left; $p<0.0001$, Kolmogorov-Smirnov test; $n=9$ ) or when NS1619 was administered alone (Fig. $4 C$, bottom right; $p<$ 0.0001 , Kolmogorov-Smirnov test, $n=5$ ). The maximum current amplitudes were plotted against the test voltages to construct $I-V$ curves (Fig. $4 D, E$ ). The $I-V$ curve in the control group revealed a slope conductance of $209 \mathrm{pS}$, which is in agreement with the conductance values reported for BK channels in other neuronal types and smooth muscle (McManus, 1991). At $+80 \mathrm{mV}$, METH significantly decreased the amplitude of the unitary cur- rent peaks by $39.9 \%$, from $19.99 \pm 2.4$ to $12.02 \pm 1.5 \mathrm{pA}$ (Fig. $4 D$; $t_{(16)}=3.0, p<0.01$, two-tailed Student's $t$ tests; groups from -60 $\mathrm{mV}$ to $+80 \mathrm{mV}: F_{(1,14)}=0.3, p>0.05$, one-way ANOVA followed by Tukey's test; $n=8$ vs 10). Consistent with the idea that METH decreases BK channel activity, application of BK channel opener NS1619 reversed the METH-induced reduction of unitary currents (Fig. $4 D ; t_{(17)}=-4.1, p<0.01$, two-tailed Student's $t$ tests; groups from -60 to $+80 \mathrm{mV}: F_{(1,14)}=0.7, p>0.05$, one-way ANOVA followed by Tukey's test; $n=8$ /group). In addition, NS1619 increased the mean amplitude of unitary current by $38.6 \%$, from $19.63 \pm 3.4$ to $31.98 \pm 5.0 \mathrm{pA}$ (Fig. $4 E$; $t_{(10)}=-2.3, p<0.05$, two-tailed Student's $t$ tests; groups from -60 to $+80 \mathrm{mV}: F_{(1,12)}=1.4, p>0.05$, one-way ANOVA followed by Tukey's test; $n=7$ vs 5 ). These data suggest that METH modulates BK channel-mediated currents in dopamine neurons.

\section{Paxilline decreases the spontaneous firing activity of} dopamine neurons

Since activation of BK channels eliminated the METH-induced reduction of unitary current peaks, we reasoned that paxillineinhibition of BK channels might influence the excitability of dopamine neurons. Therefore, we assessed the spontaneous spike activity of these neurons at resting membrane potential before 
A

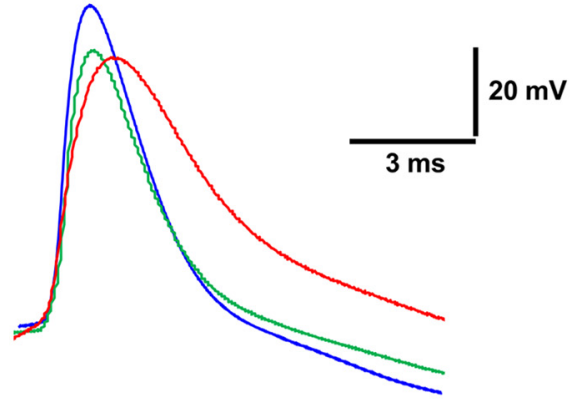

B

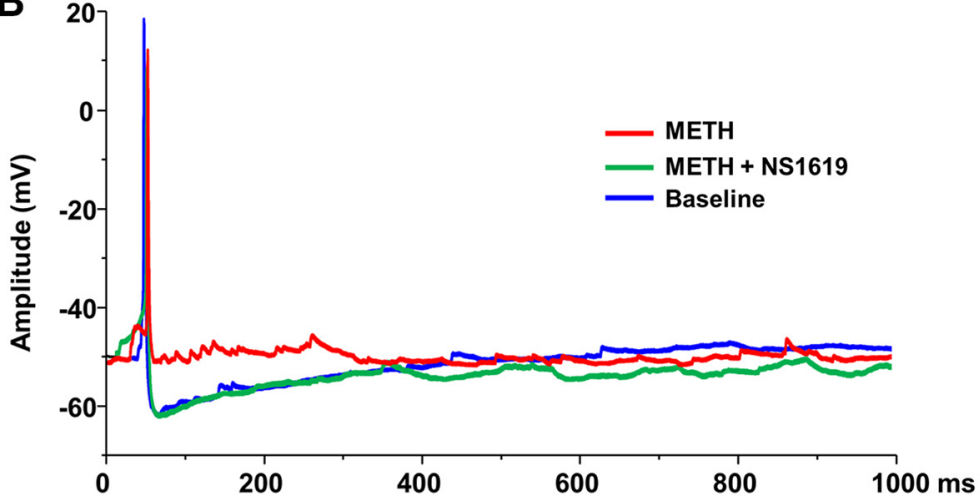

C

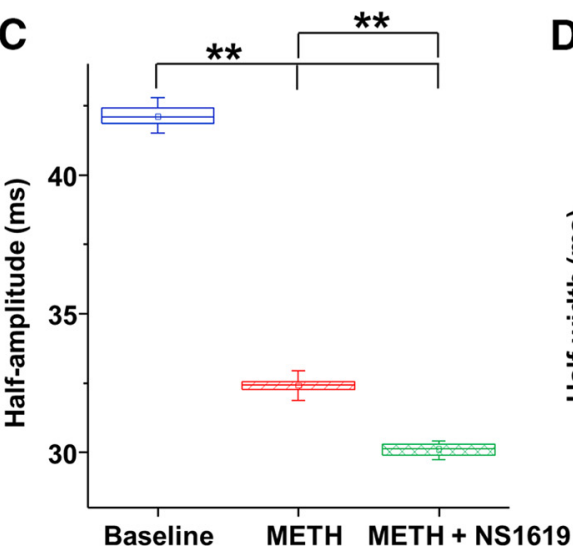

D

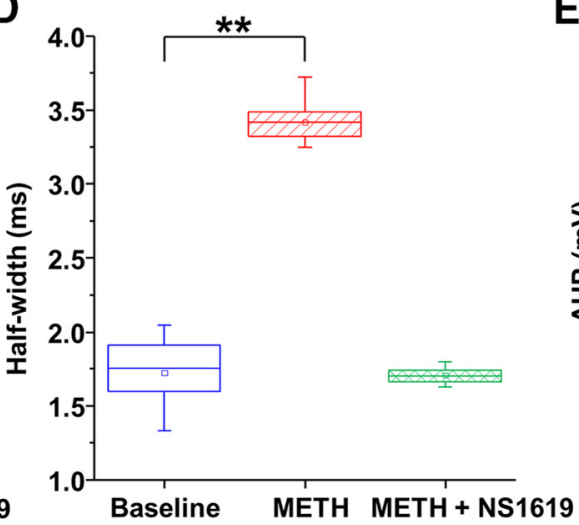

E

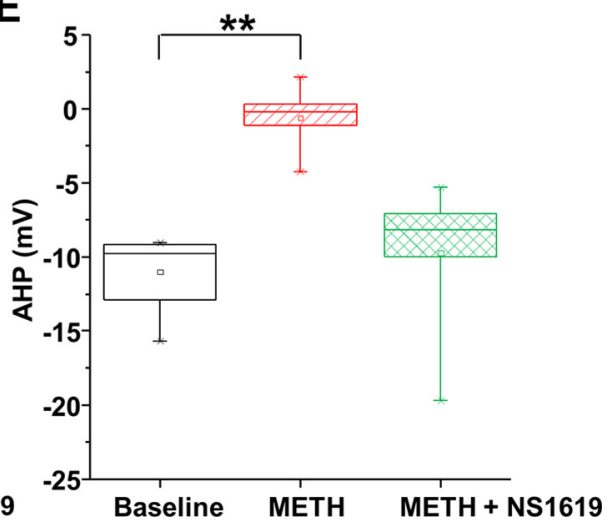

Figure 6. NS1619 attenuates METH alteration of AP repolarization and AHP. $A, B$, Representative traces of single APs in dopamine neurons in the absence of drug (blue trace), following METH exposure (10 $\mu \mathrm{M}$, red trace), and following coadministration of the BK channels activator NS1619 (10 $\mu \mathrm{m}$, green trace). C, Data are mean \pm SEM; METH and METH plus NS1619 truncated the amplitude of APs. D, Mean \pm SEM; while METH treatment broadened the spike half-width, concomitant NS1619 treatment attenuated the effect of METH on the spike half-width. $\boldsymbol{E}$, Mean \pm SEM; METH suppressed the AHP amplitude, whereas NS1619 decreased the effect of METH on AHP. Boxplot whiskers indicate maximum and minimum data points. ${ }^{* *} p<0.01$ ( $n=6$ per group).

and after paxilline administration. Paxilline progressively reduced the spontaneous spike activity of these neurons (Fig. $5 A-C)$. There was no significant difference between the paxillineinduced and METH-induced reduction of the magnitude of firing frequency, determined as the percentage of the mean baseline $\left(77.9 \pm 7.1 \%\right.$ in paxilline; $77.8 \pm 10.3 \%$ in $\mathrm{METH} ; t_{(17)}=0.008$, $p>0.05$, two-tailed Student's $t$ tests; $n=9$ vs 10), but the onset of paxilline-induced reduction of firing frequency occurred earlier $\left(1.45 \pm 0.3 \mathrm{~min}\right.$ vs $3.8 \pm 0.6 \mathrm{~min} ; t_{(15)}=3.8, p<0.01$, two-tailed Student's $t$ tests; $n=8$ vs 9). Moreover, similar to METH, paxilline significantly depolarized the membrane potential (baseline: $-48.5 \pm 0.1 \mathrm{mV}$; paxilline: $-43.1 \pm 1.7 \mathrm{mV} ; t_{(16)}=-2.9, p<$ 0.05 , two-tailed Student's $t$ tests; $n=9)$, increased the half-width (Fig. $5 D, E ; D: t_{(16)}=-3.8, p<0.01, p<0.01$, two-tailed Student's $t$ tests; $E: p<0.0001$, Kolmogorov-Smirnov test), and increased the coefficient of variation of interspike intervals (Fig. $5 F ; t_{(16)}=-2.7, p<0.05$, two-tailed Student's $t$ tests).

Activation of BK channels circumvents METH-induced reduction of spontaneous spike activity in dopamine neurons and partially restores METH-induced reduction of AHP amplitude and AP width

We found that although NS1619 could not restore METHinduced reduction of AP amplitude [Fig. $6 A, C: F_{(2,57)}=9397.7$, $p<0.01$, one-way ANOVA followed by Tukey's test; $n=6$ neurons (20 spikes)/group], NS1619 reversed the effect of METH on AP width. There was no significant difference between the baseline AP width and the AP width after METH plus NS1619 treat- ment [Fig. $6 A, D: F_{(2,56)}=896.8, p<0.01$, one-way ANOVA followed by Tukey's test; $n=6$ neurons (baseline, 19 spikes; METH, 20 spikes; METH + NS1619, 20 spikes)]. As compared with METH alone, coapplication of NS1619 and METH partially diminished the effect of METH-induced suppression of AHP amplitude [Fig. $6 B, E ; F_{(2,41)}=48.7, p<0.01$, one-way ANOVA followed by Tukey's test; $n=6$ neurons (baseline, 15 spikes; METH, 14 spikes; METH + NS1619, 15 spikes)]. Next, we investigated whether activation of the BK channel prevents METHinduced suppression of spontaneous spike activity of dopamine neurons. Representative responses of spontaneous spike activity following METH treatment and following combined application of METH and NS1619 are shown in Figure 7A. Consistent with Figure 1, METH significantly increased the firing frequency when applied alone, but application of NS1619 $(10 \mu \mathrm{M})$ prevented the METH-induced delayed reduction of firing activity (Fig. $7 B, C$; $B$ : $F_{(2,24)}=16.5, p<0.01$, one-way ANOVA followed by Tukey's test; $C: p<0.0001$, Kolmogorov-Smirnov test, baseline or NS1619 vs METH; $n=9$ ), and restored the AP half-width to control levels (Fig. $7 D, E ; D: F_{(2,24)}=35.2, p<0.01$, one-way ANOVA, followed by Tukey's test; $E$ : Kolmogorov-Smirnov test, $p<0.0001$, baseline or NS1619 vs METH; $n=9$ ). In addition, NS1619 prevented the METH-induced membrane depolarization (baseline: $-45.5 \pm 1.2 \mathrm{mV}$; METH alone: $-40.1 \pm 1.5 \mathrm{mV}$, $t_{(16)}=-3.1, p<0.01$; METH plus NS1619: $-44.2 \pm 1.7 \mathrm{mV}$, $t_{(16)}=-0.7, p>0.05$, two-tailed Student's $t$ tests; $n=9$ ), while the coefficient of variation of the interspike intervals did not significantly discriminate between the groups (Fig. $7 F$ ). 


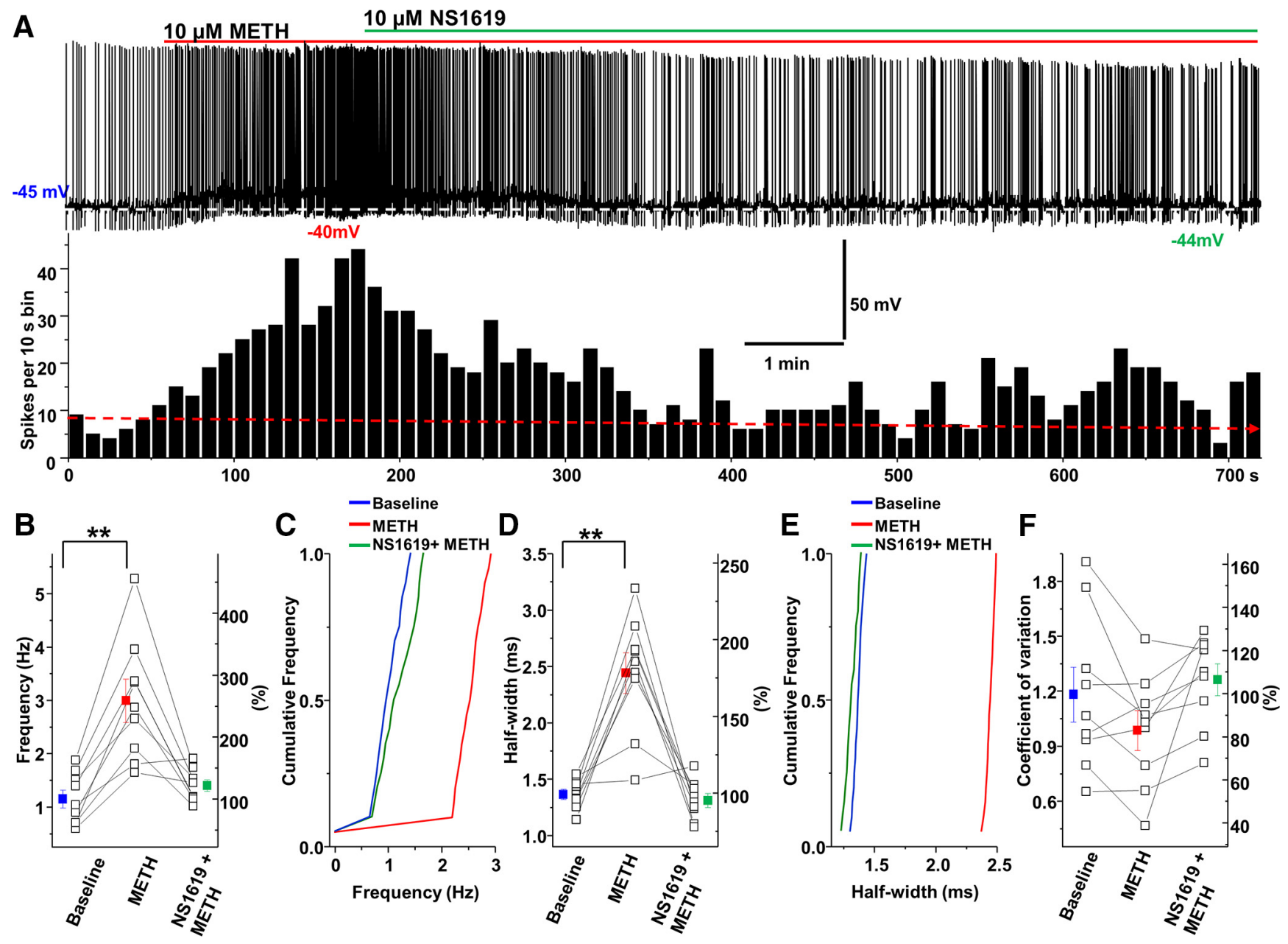

Figure 7. NS1619 attenuates the effect of METH on the spontaneous firing activity of dopamine neurons. $A$, Top, Representative trace from a spontaneously active dopamine neuron before and after application of METH followed by NS1619 treatment (10 $\mu \mathrm{M})$. Bottom, Rate histogram of the trace above. $\boldsymbol{B}, \boldsymbol{C}$, Data are mean \pm SEM; NS1619 diminished the effect of METH on the spontaneous firing frequency. $\boldsymbol{D}, \boldsymbol{E}$, Mean \pm SEM; while METH increased the spike half-width, NS1619 attenuated the effect of METH on the spike half-width. $\boldsymbol{F}$, Mean \pm SEM; the coefficients of variation of the interspike intervals were not significantly different among the three groups: baseline, METH, and NS1619. In $\boldsymbol{B}, \boldsymbol{D}$, and $\boldsymbol{F}$, the left $y$-axis shows absolute values, and the right $y$-axis shows normalized values. ${ }^{* *} p<0.01$ ( $n=9$ per group).

Combined application of METH and paxilline occludes the effects of METH on the spontaneous firing activity of dopamine neurons

The results so far suggest that activation of BK channels circumvents METH-induced reduction of spontaneous spike activity in dopamine neurons. Therefore, METH inhibition of spontaneous firing activity of dopamine neurons could be through suppression of BK channel activity. If that were the case, then combined METH and paxilline treatment should occlude the effects of the other, and vice versa. As shown in Figure 8, combined METH and paxilline treatment markedly increased the spontaneous firing activity of dopamine neurons (Fig. $8 A-C ; B: t_{(20)}=-2.9, p<$ 0.01 , two-tailed Student's $t$ tests; $C: p<0.0001$, KolmogorovSmirnov test; $n=11$ /group). Interestingly, contrary to the effect of each drug alone, combined METH and paxilline significantly decreased the AP half-width (Fig. $8 D, E ; D: t_{(20)}=4.1, p<0.01$, two-tailed Student's $t$ tests; E: $p<0.0001$, Kolmogorov-Smirnov test; $n=11$ /group), had no effect on the coefficient of variation of interspike intervals, and did not change the membrane potentials (baseline, before drug application: $-46.7 \pm 1.5 \mathrm{mV}$; METH + paxilline: $-45.3 \pm 1.7 \mathrm{mV}, t_{(20)}=1.0, p>0.05$, two-tailed Student's $t$ tests; $n=11 /$ group). These data support the idea that
METH-induced reduction of spontaneous firing activity of dopamine neurons is mediated through BK channels.

METH reduces membrane levels of BK- $\alpha$ subunits via a protein kinase $\mathrm{C}$-dependent mechanism

The BK- $\alpha$ subunit is the pore-forming unit of the BK channel (Knaus et al., 1994), and it has been shown that there is a direct relationship between $\mathrm{BK}$ channel regulation of neuronal excitability and the level of BK- $\alpha$ subunits at the surface membrane (Shruti et al., 2012; Chen et al., 2013; Cox et al., 2014). Therefore, we examined the possibility that METH-mediated suppression of neuronal activity is due to METH-induced reduction of the BK- $\alpha$ subunit level at the plasma membrane. Using Western blot analysis, we first confirmed endogenous expression of BK- $\alpha$ subunits in mice midbrain and striatum, two brain regions containing the largest number of dopamine neurons (Fig. $9 C ; n=4$ ). We then used immunostaining of BK- $\alpha$ subunits in cultured mice midbrain dopamine neurons to identify the membrane pool of BK- $\alpha$ subunits and to examine whether METH influences membrane distribution of BK- $\alpha$ subunits. To identify the plasma membrane, we used a fluorophore-conjugated cholera-toxin B subunit (Alexa Fluor 555 conjugate), which binds to ganglioside GM1 at the 
A $10 \mu \mathrm{M}$ METH $+10 \mu \mathrm{M}$ paxilline
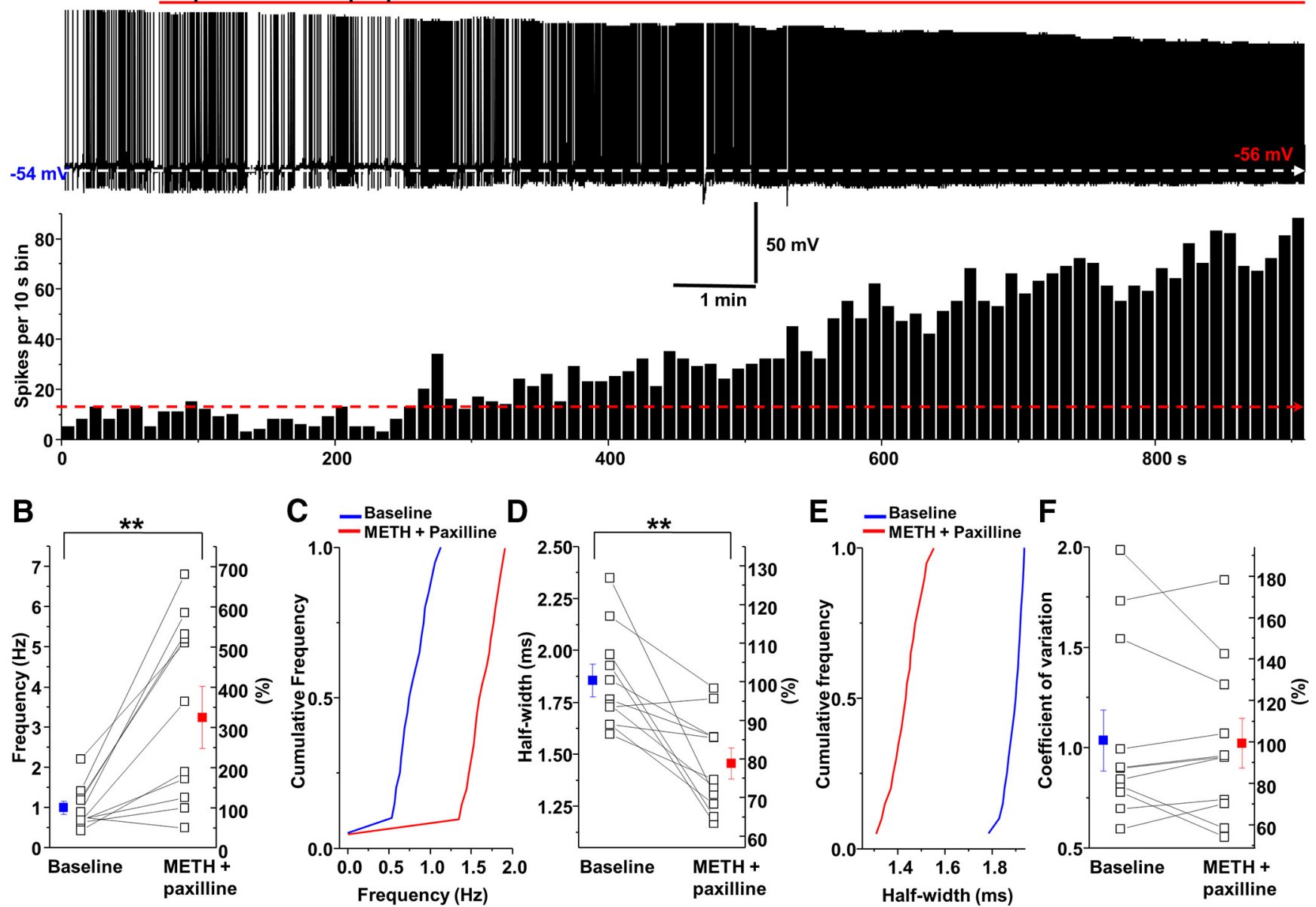

Figure 8. Simultaneous application of METH and paxilline increased the spontaneous firing activity of dopamine neurons. $\boldsymbol{A}$, Top, Representative trace from a spontaneously active dopamine neuron before and after application of METH and paxilline. Bottom, Rate histogram from the above trace. $\boldsymbol{B}, \boldsymbol{C}$, Data are mean \pm SEM; analysis of the frequency of the spontaneous firing activity of dopamine neurons with combined treatment of paxilline and METH. $\boldsymbol{D}, \boldsymbol{E}$, Mean \pm SEM; the spike half-width decreased after bath application of combined paxilline and METH. $\boldsymbol{F}$, Interspike intervals were not significantly different. $\operatorname{In} \boldsymbol{B}, \boldsymbol{D}$, and $\boldsymbol{F}$, the left $y$-axis shows absolute values, and the right $y$-axis shows normalized values. ${ }^{* *} p<0.01$ ( $n=11$ per group).

membrane (Fig. 9A, middle; Sandvig and van Deurs, 2000). Next, we identified the BK- $\alpha$ subunits in dopamine neurons by immunolabeling against BK- $\alpha$ subunits (Fig. 9A, left). Examinations of mean ICQ values at the soma $(0.13 \pm 0.006)$ and the neurites $(0.24 \pm 0.01)$ revealed that $\mathrm{BK}-\alpha$ subunits are colocalized with GM1 at the surface membrane of dopamine neurons (Fig. 9A, right; $B)$. METH exposure significantly reduced the ICQ values to $0.09 \pm 0.05$ at $15 \mathrm{~min}$ and to $0.05 \pm 0.009$ at $30 \mathrm{~min}$ for the soma and $0.17 \pm 0.011$ at $15 \mathrm{~min}$ and to $0.16 \pm 0.012$ at $30 \mathrm{~min}$ for the neurites of immunostained dopamine neurons (Fig. $9 \mathrm{~B}$; body, $F_{(2,64)}=23.8, p<0.01$; neurites, $F_{(2,64)}=10.0, p<0.01$, one-way ANOVA followed by Tukey's test; $n$ : baseline, 20; METH 15 min, 29; METH 30 min, 18).

Although results from fixed dopamine neurons suggest METH might have influenced the membrane level of BK- $\alpha$ subunits, it falls short of addressing the effect of METH on the dynamic trafficking of the channel away from the membrane. Therefore, to examine whether METH induces surface redistribution of the BK channels, we used TIRF microscopy to monitor BK channel trafficking. TIRF microscopy is an imaging technique that selectively illuminates fluorophores at or near the surface membrane. The TIRF profile of GFP- $\alpha$ subunits was examined in HEK293 cells expressing GFP- $\alpha$ subunits in the presence or absence of 10 $\mu \mathrm{M}$ METH. As shown in Figure 10, the GFP- $\alpha$ subunits' fluores- cence signal at the membrane was stable in the vehicle (external solution)-treated control group. The TIRF profile of GFP- $\alpha$ subunits was markedly reduced following METH treatment (Fig. $10 A$; top row, vehicle-treated cells; second row, METH-treated cells; Fig. $10 B ; F_{(1,180)}=126.9, p<0.01$, one-way ANOVA followed by Tukey's test; $n=5$ /group).

METH has been shown to increase the activity of protein kinase C (PKC; Sandoval et al., 2001; Shibasaki et al., 2011). In addition, $\mathrm{PKC}$ has been shown to decrease the activity of the BK channel (Schubert et al., 1999; Taguchi et al., 2000) by reducing the membrane level of BK- $\alpha$ subunits (Surguchev et al., 2012). Therefore, we tested the hypothesis that METH-mediated reduction of the GFP- $\alpha$ subunit at the membrane is due to PKC activation. The TIRF profile of GFP- $\alpha$ subunits was markedly reduced following bath application of PMA, a PKC activator $(0.1$ $\mu \mathrm{M}$; Fig. $10 A$, fourth row). Conversely, pretreatment with the PKC inhibitor BIM-I ( $1 \mu \mathrm{M}, 20 \mathrm{~min}$; Fig. 10A, third row) prevented METH-induced trafficking of GFP- $\alpha$ subunits (Fig. 10C; $F_{(1,180)}=136.7, p<0.01$, one-way ANOVA followed by Tukey's test; $n=7$ /group). Since PMA and BIM-I target multiple isoforms of $\mathrm{PKC}$, these experiments do not identify which PKC isoform is involved in GFP- $\alpha$ subunit trafficking. Nonetheless, these data support the interpretation that METH decreases the 


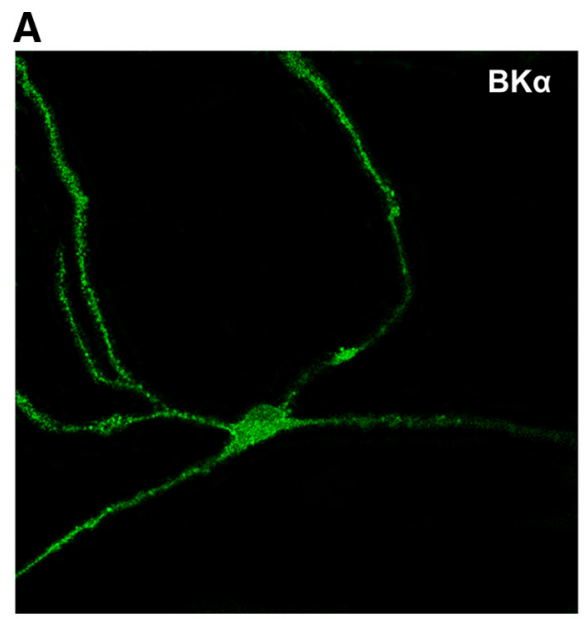

B

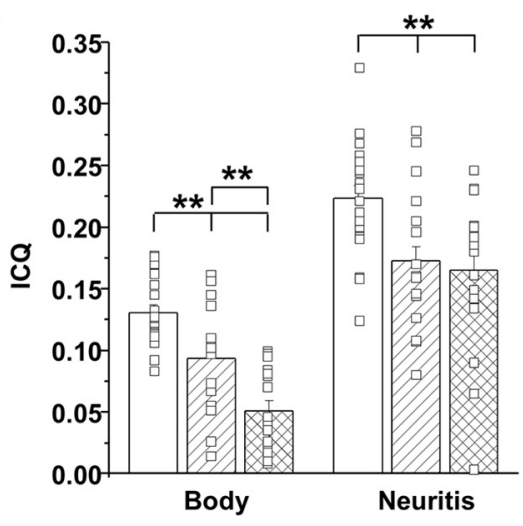

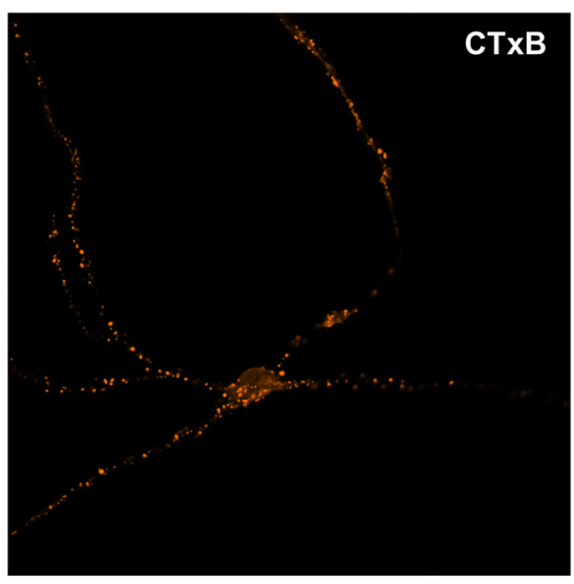

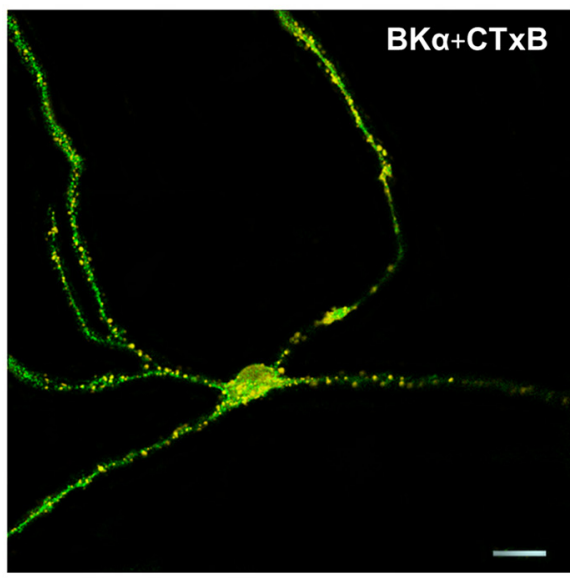

C
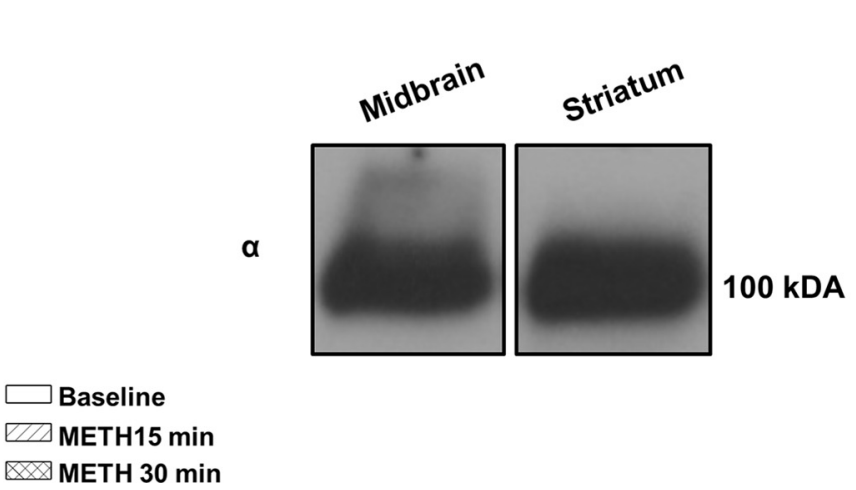

Figure 9. METH exposure reduces plasma membrane localization of the $\alpha$ subunit in dopamine neurons. $A$, Representative immunofluorescence labeling of the endogenous $\alpha$ subunits of $B K$ channels and cholera toxin subunit B-labeled (CTXB) GM1-positive microdomains at the plasma membrane of dopamine neurons. B, Data are mean \pm SEM; colocalization of $\alpha$ subunits and CTXB in the soma and neurites of dopamine neurons before and after METH treatment. $C$, Western blot analysis detects the $\alpha$ subunit of BK channels in the midbrain and striatal tissue, two brain regions containing dopamine neurons. ${ }^{* *} p<0.01$ ( $n=18,20$ or 29 per group).

activity of the BK channel by reducing cell-surface distribution of the $\alpha$ subunits via a PKC-dependent mechanism.

\section{Discussion}

In this study, we identified an unexpected and unique property of METH on intrinsic firing behavior of dopamine neurons. While we and others have shown that METH rapidly and transiently increased the spontaneous spike activity of dopamine neurons through activation of the dopamine transporter (Ingram et al., 2002; Saha et al., 2014), here we found prolonged exposure to METH progressively reduced the spontaneous firing activity of dopamine neurons, which was reversed by activation of BK channels. This effect was not due to indirect effects of METH on D1 or D2 receptor activation because these experiments were performed when D1 and D2 receptors were blocked. Both METH and paxilline, a BK channel inhibitor, broadened APs and reduced AHP (Fig. 2). Using excised patch recordings, we identified a METH-sensitive BK-mediated unitary current (Fig. 4) and found that NS1619, a BK channel opener, diminished the METH-induced suppression of spontaneous spike activity, AP broadening, and AHP reduction. These data suggest that METHinduced alteration of intrinsic firing behavior of dopamine neurons is, in part, due to regulation of BK channel activity. Live-cell TIRF microscopy and immunostaining of surface membrane BK channel- $\alpha$ subunits revealed that METH decreased the surface level of the BK- $\alpha$ subunit via a PKC-dependent mechanism (Fig.
10). Together, our results support the interpretation that BK channels in dopaminergic neurons may serve as a novel cellular target of METH.

Consistent with previous reports, we found midbrain dopamine neurons exhibit two types of firing patterns: sparse clusters (Figs. 1A, 7A) and pacemaker-like irregular single-spike activity (Figs. 5A, 8; Grace and Bunney, 1984; Tepper et al., 1987). Dopamine transporter activation by amphetamines has been shown to rapidly (within $30 \mathrm{~s}$ ) depolarize the neurons and increase the firing rate (Ingram et al., 2002; Branch and Beckstead, 2012; Saha et al., 2014). In this study, first we reproduced the existing reports regarding the effect of rapid METH exposure on the firing activity of midbrain dopamine neurons. Consistent with the literature (Ingram et al., 2002; Branch and Beckstead, 2012; Saha et al., 2014), METH rapidly (within 30 s) increased the firing frequency of dopamine neurons that reached peak firing rate after $\sim 3 \mathrm{~min}$ (Fig. 1A). Our laboratory and others have extensively characterized this early effect (1-2 min) of amphetamines on the excitability of dopamine neurons when D1 and D2 receptors are blocked (Ingram et al., 2002; Saha et al., 2014). In addition, following longer METH exposure ( $>4 \mathrm{~min}$ ), we found METH produced a time-dependent biphasic effect on the spontaneous spike activity of dopamine neurons, in which continuous METH exposure progressively decreased the firing frequency below baseline (Fig. 1A). Examination of APs revealed that METH exposure broad- 


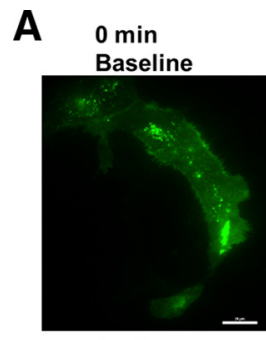

0 min

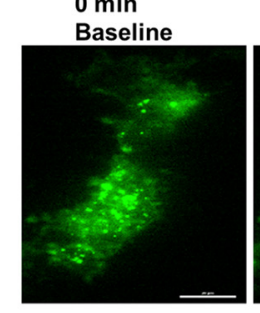

0 min
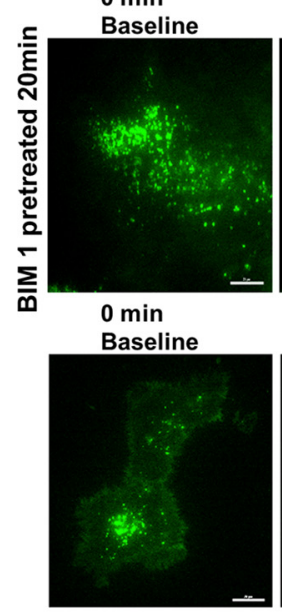

$5 \mathrm{~min}$
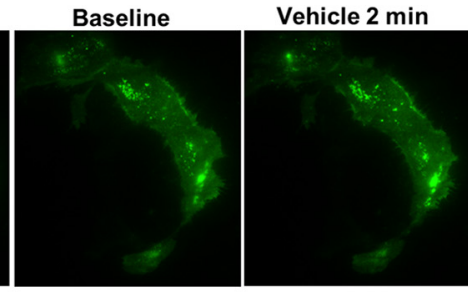

5 min
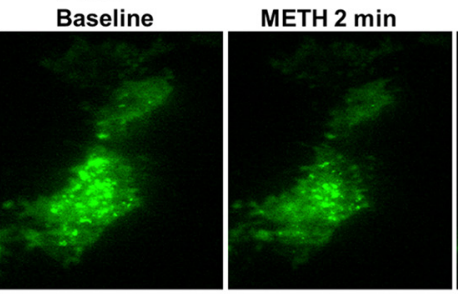

$5 \mathrm{~min}$
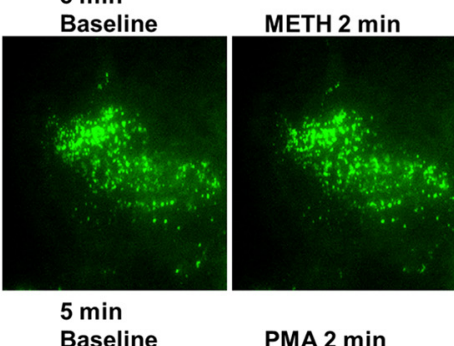

PMA 2 min
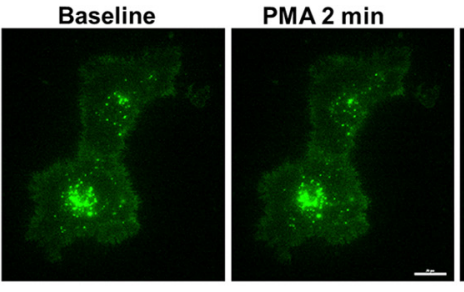
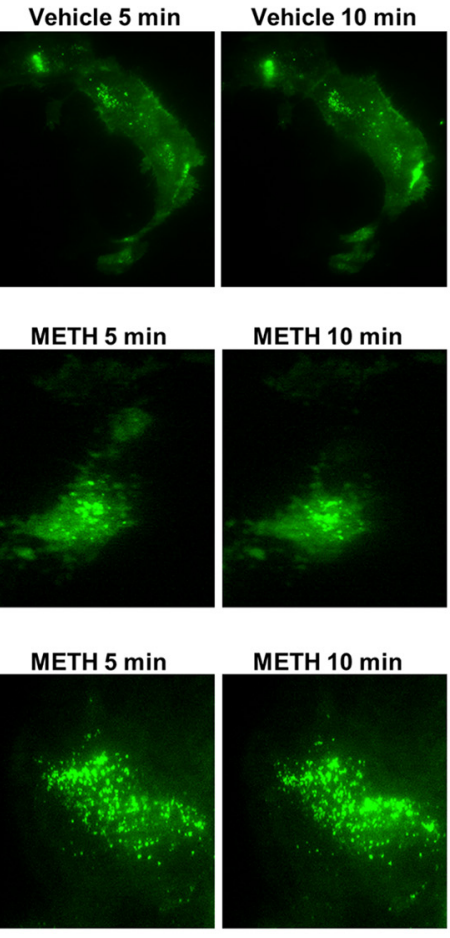

METH $10 \mathrm{~min}$

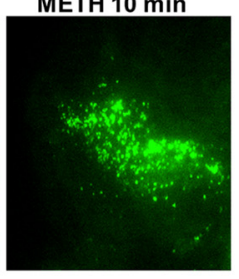

PMA 5 min
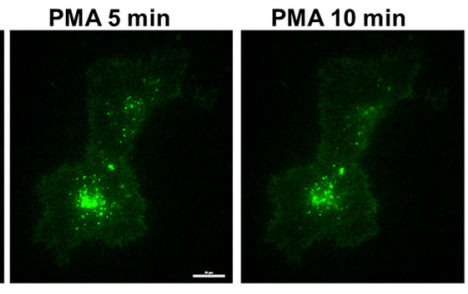

B

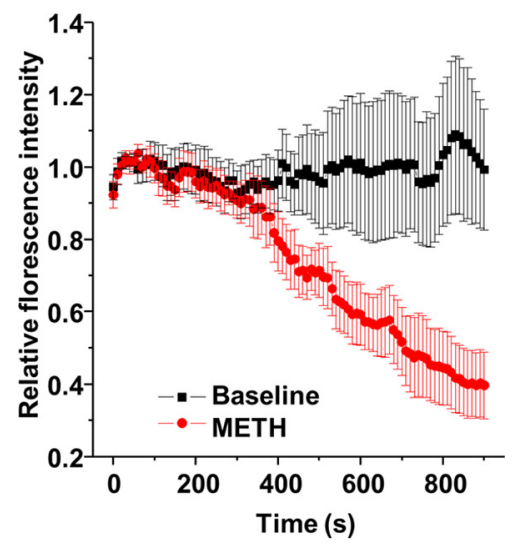

C

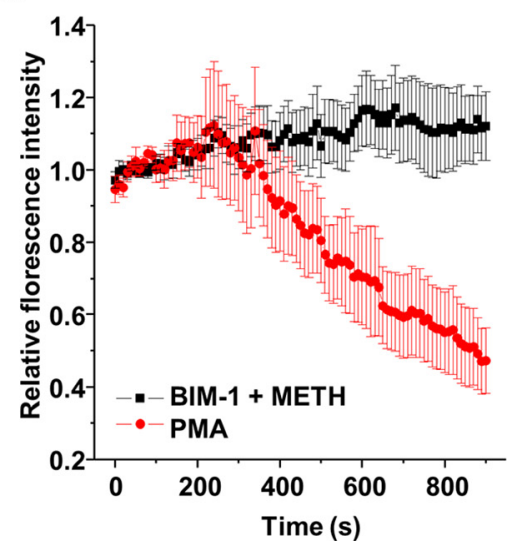

Figure 10. METH or PMA internalizes $\alpha$ subunits, while BIM-1 inhibition of PKC prevented internalization of the GFP- $\alpha$ subunit. $A$, Representative TIRF microscopy images of the GFP- $\alpha$ subunit at the plasma membrane of HEK 293 cells following vehicle, $10 \mu \mathrm{m} \mathrm{METH,} 1 \mu \mathrm{m}$ BIM-1 plus METH, or $0.1 \mu \mathrm{M}$ PMA treatment. B, C, Data are mean \pm SEM; analyses of relative fluorescent intensities at the surface membrane following vehicle, METH, METH plus BMI- 1 or PMA treatments. $N=5$ or 7 per group.

ened APs and repressed AHP (Fig. 2A,D,E); therefore, we hypothesized that METH may have influenced a $\mathrm{K}^{+}$conductance in these neurons. METH has been shown to increase the level of L-type $\mathrm{Ca}^{2+}$ channels in the frontal cortex and the limbic forebrain neurons (Shibasaki et al., 2010), leading to increased intracellular $\mathrm{Ca}^{2+}$ levels (Uramura et al., 2000). Hence, METH may regulate the excitability of dopamine neurons by altering the $\mathrm{Ca}^{2+}$-activated BK channels, known to modulate neuronal activity.

BK channels are involved in AP repolarization in several neuronal types (Adams et al., 1982; Lancaster and Nicoll, 1987; Storm, 1990; Lin et al., 2014). Consistent with these reports, we found BK channels are expressed in dopamine neurons (Fig. 9) and contribute to AP repolarization and AHP, where blockade of BK channels increased the half-width of APs and repressed AHP (Smart, 1987; Faber and Sah, 2002; Lin et al., 2014; Fig. 2). Since the effects of METH on AP width and AHP were similar to blockade of BK channels, we investigated METH regulation of BK-mediated currents in dopamine neurons. Whole-cell patchclamp recordings (Fig. 3) and single-channel analysis (Fig. 4) support the interpretation that BK channels in dopamine neurons are activated at membrane potentials $>+20 \mathrm{mV}$ with a conductance of $209 \mathrm{pS}$, which are comparable to reported values for BK channel properties in other neurons (Smart, 1987; Francio- lini, 1988; Gola et al., 1992; Lin et al., 2014). While the BK channel blocker paxilline almost completely repressed the currents, the BK channel opener NS1619 enhanced the current amplitude and frequency. Consistent with the idea that METH inhibits BK channel activity, METH suppressed the amplitude and frequency of BK unitary currents, whereas NS1619 reduced the influence of METH on these unitary currents (Fig. 4). Together, these observations strongly support the notion that METH inhibits the activity of BK channels in dopamine neurons.

Although neuronal potassium channels are usually regarded as inhibitory (i.e., reducing neuronal excitability; Lancaster and Nicoll, 1987; Alger and Williamson, 1988; Storm, 1990), increased neuronal excitability are reported following blockade of BK channels in dissociated Purkinje neurons (Swensen and Bean, 2003), rat dorsal root ganglia neurons (Zhang et al., 2003), and spontaneous firing of vestibular nucleus neurons (Nelson et al., 2003). Consistently, while BK channel antagonists have shown to reduce burst firing in abnormally active neurons (Jin et al., 2000; Shruti et al., 2008), the firing activity of Purkinje neurons is decreased in $B K^{-1-}$ mice (Sausbier et al., 2004; Chen et al., 2010). In the present study, we found that the BK channel blocker paxilline inhibited the firing rate of dopamine neurons (Fig. 5). This suggests activation of BK channels in dopamine neurons can facilitate excitability, rather than having an inhibitory role. These data 
are consistent with the reports showing that activation of BK channels enhance the excitability of adrenal chromaffin cells (Solaro et al., 1995; Lovell and McCobb, 2001), CA1 hippocampal pyramidal cells ( $\mathrm{Gu}$ et al., 2007), and parasympathetic cardiac motoneurons in the nucleus ambiguus (Lin et al., 2014). Similarly, enhanced BK channel activity has been linked to neuronal hyperexcitability and epilepsy in cortical neurons (Brenner et al., 2005; Lorenz et al., 2007; Shruti et al., 2008; Wang et al., 2009). Thus, METH reduction of the firing frequency of dopamine neurons might be due to decreased BK channel activity. If that were the case, then enhancing the activity of BK channels should attenuate the effects of METH. To examine this, we compared the effects of METH in the presence or absence of NS1619 on the AP properties and spontaneous spike activity. We found that the BK channel opener not only prevented METH-induced AP broadening, but also restored AHP to baseline levels (Fig. 6). In addition, NS1619 prevented METH reduction of spontaneous spike activity (Fig. 7). It is possible that METH suppression of AP amplitude (Figs. 2, 6) is due to its indirect effect on other channels and transporters known to influence delayed rectifier potassium current (Van Goor et al., 2001; Petrik et al., 2011).

Next, we examined the underlying mechanism for the decreased BK channel activity following continuous METH exposure. As shown in Figure 9, BK- $\alpha$ channels are found in dopamine neurons and continuous METH exposure decreased cell-surface levels of BK- $\alpha$ channels and thus their activity (Fig. $3 D, E$ ). Structurally, BK channels are composed of $\geq 2$ noncovalently associated subunits: the pore-forming $\alpha$ subunit (four $\alpha$ subunits form the channel pore) and the regulatory $\beta$ subunits (Knaus et al., 1994; Brenner et al., 2000; Lu et al., 2006). BK channel complexes containing the $\alpha$ subunits are found abundantly in neurons, where they regulate APs and neurotransmitter release (Weiger et al., 2002; Lu et al., 2006). To maintain the scope of the current study, we did not examine the distribution of other auxiliary subunits of the BK channel. It is possible that multiple auxiliary subunits of the BK channel are expressed in dopamine neurons, where they modulate dopamine neuron activity. These subunits will be the focus of our future studies.

The intrinsic gating properties of $\mathrm{Ca}^{2+}$-activated $\mathrm{K}^{+}$channels and their trafficking are dynamically modulated by kinases (Chae and Dryer, 2005; Toro et al., 2006; Zarei et al., 2007). METH has been shown to increase the activity of such kinases as protein kinase A (Crawford et al., 2003; Lin et al., 2010) and PKC (Sandoval et al., 2001; Shibasaki et al., 2011). Therefore, it is possible that METH-induced phosphorylation of the $\alpha$ subunit or $\beta$ subunit of the BK channel leads to increased trafficking and/or altered gating properties of the channel. This idea is supported by the findings that both METH and PMA increased trafficking of GFP- $\alpha$ subunits (Fig. 10), whereas PKC inhibition reversed METH-induced internalization of GFP- $\alpha$ subunits (Fig. 10). Therefore, METH suppression of the outward current shown in Figure $3 D, E$ might be due to $\mathrm{METH}$-induced internalization of GFP- $\alpha$ subunits. PMA and BIM-I target multiple isoforms of PKC. Since PKC isoforms have been shown to impart signaling specificity (Lanuza et al., 2014), it would be of interest in future studies to determine which PKC isoform is involved in the $\mathrm{METH}$ regulation of $\mathrm{BK}$ channel activity.

In summary, BK channels in dopamine neurons can facilitate neuronal excitability, and METH may increase cell-surface redistribution of the BK- $\alpha$ subunit to inhibit the activity of dopamine neurons. Because METH-induced increases in the firing activity of dopamine neurons is transient and is followed by a prolonged decrease in firing activity, our data support the idea that METH inhibition of dopamine uptake and stimulation of dopamine efflux are two central mechanisms for the prolonged stimulation of dopamine neurotransmission and behavioral responses to METH.

\section{References}

Adams PR, Constanti A, Brown DA, Clark RB (1982) Intracellular $\mathrm{Ca}^{2+}$ activates a fast voltage-sensitive $\mathrm{K}^{+}$current in vertebrate sympathetic neurones. Nature 296:746-749. CrossRef Medline

Alger BE, Williamson A (1988) A transient calcium dependent potassium component of the epileptiform burst after-hyperpolarization in rat hippocampus. J Physiol 399:191-205. CrossRef Medline

Baucum AJ 2nd, Rau KS, Riddle EL, Hanson GR, Fleckenstein AE (2004) Methamphetamine increases dopamine transporter higher molecular weight complex formation via a dopamine- and hyperthermia-associated mechanism. J Neurosci 24:3436-3443. CrossRef Medline

Bennett BA, Hollingsworth CK, Martin RS, Harp JJ (1998) Methamphetamine-induced alterations in dopamine transporter function. Brain Res 782:219-227. CrossRef Medline

Branch SY, Beckstead MJ (2012) Methamphetamine produces bidirectional, concentration-dependent effects on dopamine neuron excitability and dopamine-mediated synaptic currents. J Neurophysiol 108:802-809. CrossRef Medline

Brenner R, Peréz GJ, Bonev AD, Eckman DM, Kosek JC, Wiler SW, Patterson AJ, Nelson MT, Aldrich RW (2000) Vasoregulation by the betal subunit of the calcium-activated potassium channel. Nature 407:870-876. CrossRef Medline

Brenner R, Chen QH, Vilaythong A, Toney GM, Noebels JL, Aldrich RW (2005) BK channel $\beta 4$ subunit reduces dentate gyrus excitability and protects against temporal lobe seizures. Nat Neurosci 8:1752-1759. CrossRef Medline

Brown JM, Hanson GR, Fleckenstein AE (2000) Methamphetamine rapidly decreases vesicular dopamine uptake. J Neurochem 74:2221-2223. Medline

Chae KS, Dryer SE (2005) The p38 mitogen-activated protein kinase pathway negatively regulates $\mathrm{Ca}^{2+}$-activated $\mathrm{K}^{+}$channel trafficking in developing parasympathetic neurons. J Neurochem 94:367-379. CrossRef Medline

Chen C, Xu Y, Zhang J, Zhu J, Zhang J, Hu N, Guan H (2013) Altered expression of nNOS/NIDD in the retina of a glaucoma model of DBA/2J mice and the intervention by nNOS inhibition. J Mol Neurosci 51:47-56. CrossRef Medline

Chen X, Kovalchuk Y, Adelsberger H, Henning HA, Sausbier M, Wietzorrek G, Ruth P, Yarom Y, Konnerth A (2010) Disruption of the olivocerebellar circuit by Purkinje neuron-specific ablation of BK channels. Proc Natl Acad Sci U S A 107:12323-12328. CrossRef Medline

Cox DH (2014) Modeling a $\mathrm{Ca}^{2+}$ channel/ $\mathrm{BK}_{\mathrm{Ca}}$ channel complex at the single-complex level. Biophys J 107:2797-2814. CrossRef Medline

Cox N, Toro B, Pacheco-Otalora LF, Garrido-Sanabria ER, Zarei MM (2014) An endoplasmic reticulum trafficking signal regulates surface expression of $\beta 4$ subunit of a voltage- and $\mathrm{Ca}^{2+}$-activated $\mathrm{K}^{+}$channel. Brain Res 1553:12-23. CrossRef Medline

Crawford CA, Williams MT, Newman ER, McDougall SA, Vorhees CV (2003) Methamphetamine exposure during the preweanling period causes prolonged changes in dorsal striatal protein kinase A activity, dopamine D2-like binding sites, and dopamine content. Synapse 48:131137. CrossRef Medline

Faber ES, Sah P (2002) Physiological role of calcium-activated potassium currents in the rat lateral amygdala. J Neurosci 22:1618-1628. Medline

Fakler B, Adelman JP (2008) Control of $\mathrm{K}_{\mathrm{Ca}}$ channels by calcium nano/ microdomains. Neuron 59:873-881. CrossRef Medline

Fischer JF, Cho AK (1979) Chemical release of dopamine from striatal homogenates: evidence for an exchange diffusion model. J Pharmacol Exp Ther 208:203-209. Medline

Franciolini F (1988) Calcium and voltage dependence of single $\mathrm{Ca}^{2+}$ activated $\mathrm{K}^{+}$channels from cultured hippocampal neurons of rat. Biochim Biophys Acta 943:419-427. CrossRef Medline

Gola M, Niel JP, Bessone R, Fayolle R (1992) Single channel and whole-cell recordings from non-dissociated sympathetic neurons in rabbit coeliac ganglia. J Neurosci Methods 43:13-22. CrossRef Medline

Goodwin JS, Larson GA, Swant J, Sen N, Javitch JA, Zahniser NR, De Felice LJ, Khoshbouei H (2009) Amphetamine and methamphetamine differen- 
tially affect dopamine transporters in vitro and in vivo. J Biol Chem 284: 2978-2989. CrossRef Medline

Grace AA, Bunney BS (1984) The control of firing pattern in nigral dopamine neurons: burst firing. J Neurosci 4:2877-2890. Medline

Gu N, Vervaeke K, Storm JF (2007) BK potassium channels facilitate highfrequency firing and cause early spike frequency adaptation in rat CA1 hippocampal pyramidal cells. J Physiol 580:859-882. CrossRef Medline

Haughey HM, Fleckenstein AE, Hanson GR (1999) Differential regional effects of methamphetamine on the activities of tryptophan and tyrosine hydroxylase. J Neurochem 72:661-668. CrossRef Medline

Hille B (2001) Ion channels of excitable membranes, 3rd ed. Sunderland, MA: Sinauer.

Ingram SL, Prasad BM, Amara SG (2002) Dopamine transporter-mediated conductances increase excitability of midbrain dopamine neurons. Nat Neurosci 5:971-978. CrossRef Medline

Jin W, Sugaya A, Tsuda T, Ohguchi H, Sugaya E (2000) Relationship between large conductance calcium-activated potassium channel and bursting activity. Brain Res 860:21-28. CrossRef Medline

Kiehn O, Harris-Warrick RM (1992) Serotonergic stretch receptors induce plateau properties in a crustacean motor neuron by a dual-conductance mechanism. J Neurophysiol 68:485-495. Medline

Knaus HG, Garcia-Calvo M, Kaczorowski GJ, Garcia ML (1994) Subunit composition of the high conductance calcium-activated potassium channel from smooth muscle, a representative of the mSlo and slowpoke family of potassium channels. J Biol Chem 269:3921-3924. Medline

Kogan FJ, Nichols WK, Gibb JW (1976) Influence of methamphetamine on nigral and striatal tyrosine hydroxylase activity and on striatal dopamine levels. Eur J Pharmacol 36:363-371. CrossRef Medline

Lancaster B, Nicoll RA (1987) Properties of two calcium-activated hyperpolarizations in rat hippocampal neurones. J Physiol 389:187-203. CrossRef Medline

Lanuza MA, Santafe MM, Garcia N, Besalduch N, Tomàs M, Obis T, Priego M, Nelson PG, Tomàs J (2014) Protein kinase C isoforms at the neuromuscular junction: localization and specific roles in neurotransmission and development. J Anat 224:61-73. CrossRef Medline

Lara J, Acevedo JJ, Onetti CG (1999) Large-conductance $\mathrm{Ca}^{2+}$-activated potassium channels in secretory neurons. J Neurophysiol 82:1317-1325. Medline

Latorre R, Brauchi S (2006) Large conductance $\mathrm{Ca}^{2+}$-activated $\mathrm{K}^{+}$(BK) channel: activation by $\mathrm{Ca}^{2+}$ and voltage. Biol Res 39:385-401. Medline

Li Q, Lau A, Morris TJ, Guo L, Fordyce CB, Stanley EF (2004) A syntaxin 1, $\mathrm{G} \alpha_{\mathrm{o}}$, and N-type calcium channel complex at a presynaptic nerve terminal: analysis by quantitative immunocolocalization. J Neurosci 24:40704081. CrossRef Medline

Lin M, Hatcher JT, Wurster RD, Chen QH, Cheng ZJ (2014) Characteristics of single large-conductance $\mathrm{Ca}^{2+}$-activated $\mathrm{K}^{+}$channels and their regulation of action potentials and excitability in parasympathetic cardiac motoneurons in the nucleus ambiguus. Am J Physiol Cell Physiol 306: C152-C166. CrossRef Medline

Lin PL, Tsai MC, Lu GL, Lu DY, Chuang CM, Yang HY, Huang SS, Chen YH (2010) Ecstasy and methamphetamine elicit action potential bursts via different mechanisms in a central snail neuron. Neurotoxicology 31:2641. CrossRef Medline

Lorenz S, Heils A, Kasper JM, Sander T (2007) Allelic association of a truncation mutation of the KCNMB3 gene with idiopathic generalized epilepsy. Am J Med Genet B Neuropsychiatr Genet 144B:10-13. CrossRef Medline

Lovell PV, McCobb DP (2001) Pituitary control of BK potassium channel function and intrinsic firing properties of adrenal chromaffin cells. J Neurosci 21:3429-3442. Medline

Lu R, Alioua A, Kumar Y, Eghbali M, Stefani E, Toro L (2006) MaxiK channel partners: physiological impact. J Physiol 570:65-72. CrossRef Medline

McManus OB (1991) Calcium-activated potassium channels: regulation by calcium. J Bioenerg Biomembr 23:537-560. CrossRef Medline

Misonou H, Menegola M, Buchwalder L, Park EW, Meredith A, Rhodes KJ, Aldrich RW, Trimmer JS (2006) Immunolocalization of the $\mathrm{Ca}^{2+}$ activated $\mathrm{K}+$ channel Slo1 in axons and nerve terminals of mammalian brain and cultured neurons. J Comp Neurol 496:289-302. CrossRef Medline

Nelson AB, Krispel CM, Sekirnjak C, du Lac S (2003) Long-lasting increases in intrinsic excitability triggered by inhibition. Neuron 40:609-620. CrossRef Medline
Petrik D, Wang B, Brenner R (2011) Modulation by the BK accessory $\beta 4$ subunit of phosphorylation-dependent changes in excitability of dentate gyrus granule neurons. Eur J Neurosci 34:695-704. CrossRef Medline

Saha K, Sambo D, Richardson BD, Lin LM, Butler B, Villarroel L, Khoshbouei $\mathrm{H}$ (2014) Intracellular methamphetamine prevents the dopamineinduced enhancement of neuronal firing. J Biol Chem 289:22246-22257. CrossRef Medline

Salkoff L, Butler A, Ferreira G, Santi C, Wei A (2006) High-conductance potassium channels of the SLO family. Nat Rev Neurosci 7:921-931. CrossRef Medline

Sandoval V, Riddle EL, Ugarte YV, Hanson GR, Fleckenstein AE (2001) Methamphetamine-induced rapid and reversible changes in dopamine transporter function: an in vitro model. J Neurosci 21:1413-1419. Medline

Sandvig K, van Deurs B (2000) Entry of ricin and Shiga toxin into cells: molecular mechanisms and medical perspectives. EMBO J 19:5943-5950. CrossRef Medline

Sausbier M, Hu H, Arntz C, Feil S, Kamm S, Adelsberger H, Sausbier U, Sailer CA, Feil R, Hofmann F, Korth M, Shipston MJ, Knaus HG, Wolfer DP, Pedroarena CM, Storm JF, Ruth P (2004) Cerebellar ataxia and Purkinje cell dysfunction caused by $\mathrm{Ca}^{2+}$-activated $\mathrm{K}^{+}$channel deficiency. Proc Natl Acad Sci U S A 101:9474-9478. CrossRef Medline

Schubert R, Noack T, Serebryakov VN (1999) Protein kinase C reduces the KCa current of rat tail artery smooth muscle cells. Am J Physiol 276: C648-C658. Medline

Shao LR, Halvorsrud R, Borg-Graham L, Storm JF (1999) The role of BKtype $\mathrm{Ca}^{2+}$-dependent $\mathrm{K}^{+}$channels in spike broadening during repetitive firing in rat hippocampal pyramidal cells. J Physiol 521:135-146. CrossRef Medline

Sharpe AL, Varela E, Bettinger L, Beckstead MJ (2015) Methamphetamine self-administration in mice decreases GIRK channel-mediated currents in midbrain dopamine neurons. Int J Neuropsychopharmacol 18:pii: pyu073. CrossRef Medline

Shibasaki M, Kurokawa K, Ohkuma S (2010) Upregulation of L-type $\mathrm{Ca}(\mathrm{v}) 1$ channels in the development of psychological dependence. Synapse 64:440-444. CrossRef Medline

Shibasaki M, Mizuno K, Kurokawa K, Ohkuma S (2011) L-type voltagedependent calcium channels facilitate acetylation of histone $\mathrm{H} 3$ through PKC $\gamma$ phosphorylation in mice with methamphetamine-induced place preference. J Neurochem 118:1056-1066. CrossRef Medline

Shruti S, Clem RL, Barth AL (2008) A seizure-induced gain-of-function in BK channels is associated with elevated firing activity in neocortical pyramidal neurons. Neurobiol Dis 30:323-330. CrossRef Medline

Shruti S, Urban-Ciecko J, Fitzpatrick JA, Brenner R, Bruchez MP, Barth AL (2012) The brain-specific beta4 subunit downregulates BK channel cell surface expression. PLoS One 7:e33429. CrossRef Medline

Smart TG (1987) Single calcium-activated potassium channels recorded from cultured rat sympathetic neurones. J Physiol 389:337-360. CrossRef Medline

Solaro CR, Prakriya M, Ding JP, Lingle CJ (1995) Inactivating and noninactivating $\mathrm{Ca}(2+)$ - and voltage-dependent $\mathrm{K}+$ current in rat adrenal chromaffin cells. J Neurosci 15:6110-6123. Medline

Stephans SE, Yamamoto BY (1995) Effect of repeated methamphetamine administrations on dopamine and glutamate efflux in rat prefrontal cortex. Brain Res 700:99-106. CrossRef Medline

Storm JF (1990) Potassium currents in hippocampal pyramidal cells. Prog Brain Res 83:161-187. CrossRef Medline

Surguchev A, Bai JP, Joshi P, Navaratnam D (2012) Hair cell BK channels interact with RACK1, and PKC increases its expression on the cell surface by indirect phosphorylation. Am J Physiol Cell Physiol 303:C143-C150. CrossRef Medline

Swensen AM, Bean BP (2003) Ionic mechanisms of burst firing in dissociated Purkinje neurons. J Neurosci 23:9650-9663. Medline

Taguchi K, Kaneko K, Kubo T (2000) Protein kinase C modulates $\mathrm{Ca}^{2+}$. activated $\mathrm{K}^{+}$channels in cultured rat mesenteric artery smooth muscle cells. Biol Pharm Bull 23:1450-1454. CrossRef Medline

Tepper JM, Sawyer SF, Groves PM (1987) Electrophysiologically identified nigral dopaminergic neurons intracellularly labelled with HRP: lightmicroscopic analysis. J Neurosci 7:2794-2806. Medline

Toro B, Cox N, Wilson RJ, Garrido-Sanabria E, Stefani E, Toro L, Zarei MM (2006) KCNMB1 regulates surface expression of a voltage and $\mathrm{Ca}^{2+}$. 
activated $\mathrm{K}^{+}$channel via endocytic trafficking signals. Neuroscience 142: 661-669. CrossRef Medline

Uramura K, Yada T, Muroya S, Shioda S, Shiratani T, Takigawa M (2000) Methamphetamine induces cytosolic $\mathrm{Ca}^{2+}$ oscillations in the VTA dopamine neurons. Neuroreport 11:1057-1061. CrossRef Medline

Van Goor F, Li YX, Stojilkovic SS (2001) Paradoxical role of large-conductance calcium-activated $\mathrm{K}^{+}(\mathrm{BK})$ channels in controlling action potential-driven $\mathrm{Ca}^{2+}$ entry in anterior pituitary cells. J Neurosci 21:5902-5915. Medline

Vergara C, Latorre R, Marrion NV, Adelman JP (1998) Calcium-activated potassium channels. Curr Opin Neurobiol 8:321-329. CrossRef Medline

Wang B, Rothberg BS, Brenner R (2009) Mechanism of increased BK channel activation from a channel mutation that causes epilepsy. J Gen Physiol 133:283-294. CrossRef Medline
Weiger TM, Hermann A, Levitan IB (2002) Modulation of calciumactivated potassium channels. J Comp Physiol A Neuroethol Sens Neural Behav Physiol 188:79-87. CrossRef Medline

Zarei MM, Song M, Wilson RJ, Cox N, Colom LV, Knaus HG, Stefani E, Toro L (2007) Endocytic trafficking signals in KCNMB2 regulate surface expression of a large conductance voltage and $\mathrm{Ca}(2+)$-activated $\mathrm{K}+$ channel. Neuroscience 147:80-89. CrossRef Medline

Zhang DQ, Stone JF, Zhou T, Ohta H, McMahon DG (2004) Characterization of genetically labeled catecholamine neurons in the mouse retina. Neuroreport 15:1761-1765. CrossRef Medline

Zhang XF, Gopalakrishnan M, Shieh CC (2003) Modulation of action potential firing by iberiotoxin and NS1619 in rat dorsal root ganglion neurons. Neuroscience 122:1003-1011. CrossRef Medline 